TI 2018-029/VIII

Tinbergen Institute Discussion Paper
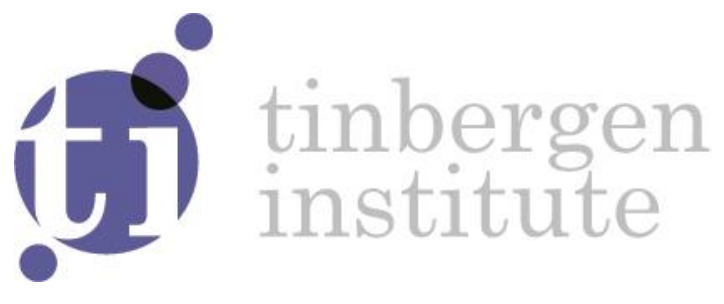

\title{
Living Apart Together: The Economic Value of Ethnic Diversity in Cities
}

Jessie Bakens ${ }^{1}$

Raymond Florax ${ }^{2}$

Henri de Groot $^{3}$

Peter Mulder ${ }^{3}$

${ }^{1}$ RSearch Centre for Education and the Labour Market, Maastricht University, The Netherlands

2 Department of Agricultural Economics, Purdue University, USA; Department of Spatial Economics, Vrije Universiteit Amsterdam, The Netherlands

${ }^{3}$ Deparment of Spatial Economics, Vrije Universiteit Amsterdam, The Netherlands 
Tinbergen Institute is the graduate school and research institute in economics of Erasmus University Rotterdam, the University of Amsterdam and VU University Amsterdam.

Contact: discussionpapers@tinbergen.nl

More TI discussion papers can be downloaded at http://www.tinbergen.nl

Tinbergen Institute has two locations:

Tinbergen Institute Amsterdam

Gustav Mahlerplein 117

1082 MS Amsterdam

The Netherlands

Tel.: +31(0)205984580

Tinbergen Institute Rotterdam

Burg. Oudlaan 50

3062 PA Rotterdam

The Netherlands

Tel.: +31(0)10408 8900 


\title{
Living Apart Together: The Economic Value of Ethnic Diversity in Cities*
}

\author{
Jessie Bakens $^{a \dagger}$, Raymond J.G.M. Florax ${ }^{b, c, d}$, Henri L.F. de Groot ${ }^{c, d}$, and Peter Mulder ${ }^{c}$ \\ ${ }^{a}$ Research Centre for Education and the Labour Market, Maastricht University, Maastricht, The Netherlands \\ ${ }^{b}$ Department of Agricultural Economics, Purdue University, West Lafayette, IN, USA \\ ${ }^{c}$ Department of Spatial Economics, Vrije Universiteit Amsterdam, Amsterdam, The Netherlands \\ ${ }^{d}$ Tinbergen Institute, Amsterdam, The Netherlands
}

\begin{abstract}
In consumer cities, the presence and location of immigrants impacts house prices through two channels, which both can be valued positively as well as negatively: (i) their presence and contribution to population diversity and (ii) the creation of immigrant-induced consumer amenities like those associated with ethnic restaurants in terms of both quantity as well as diversity. We hypothesize that these two mechanisms create a trade-off in which city dwellers want to live apart yet consume together. We derive a simple intra-city residential location model in which distance to immigrant amenities and the immigrant population in neighborhoods contribute to the explanation of differences in house prices. We use unique micro data of house prices and ethnic restaurants in the city of Amsterdam over the 1996-2011 period to estimate the trade-off between consumers' love for ethnic goods and its variety on the one hand, and ethnic residential composition on the other hand. Our results show the existence of a trade-off in which access to ethnic restaurants compensates for the negative effect of the presence of immigrants on house prices. Diversity of immigrant-induced amenities has an additional positive effect on house prices.
\end{abstract}

Keywords: amenities, diversity, immigrants, hedonic pricing, propensity score matching JEL-classification: D12, D62, J15, R10

Declarations of interest: none

\footnotetext{
${ }^{*}$ We are grateful to colleagues who have contributed through discussions and comments on previous versions of this paper at various seminars and conferences. This paper was written when the first author was affiliated with the Department of Spatial Economics, Vrije Universiteit Amsterdam, and she received funding for this research from the New Opportunities for Research Funding Co-operation Agency in Europe (NORFACE). Jessie, Peter, and Henri would like to dedicate this paper to Raymond Florax who sadly and unexpectedly passed away in the finalization stage of this paper.

${ }^{\dagger}$ Corresponding author. E-mail: j.bakens@maastrichtuniversity.nl.
} 


\section{Introduction}

For many people, cosmopolitan cities like New York, London and Amsterdam are attractive residential locations because they are rich in amenities (Glaeser et al. (2001)). Large (cosmopolitan) cities offer a relatively high product variety (Berry and Waldfogel, 2010) and they often are home to the largest concentrations of ethnic groups within a country (Borjas, 1995). Schiff (2015) shows that city size and the concentration of heterogeneous consumers in cities influence product variety. Immigrants increase the heterogeneity of consumer products and services - like ethnic restaurants, specialty food shops, hair stylists or entertainment - because immigrants have a comparative advantage in producing these goods (cf. Ottaviano and Peri, 2005; Mazzolari and Neumark, 2012) and preferences for restaurants differ by ethnicity Waldfogel (2008). Immigrant-induced amenities may thus have a positive effect on the consumer value of cities, especially if urban consumers exhibit a love for product variety (Ottaviano and Peri, 2006). But, ethnic segregation patterns observed in many large cosmopolitan cities suggest that the presence of immigrants in cities does not lead to a straightforward positive impact on local residential utility. The evidence of ethnic sorting patterns often can only be partly explained by socioeconomic and demographic differences between ethnicities, and may thus signal a negative utility effect of ethnic diversity in the local population composition on individual (native) people (Hårsman and Quigley, 1995; Bayer et al. 2004, Ioannides and Zabel (2008), Card et al., 2008, De La Roca et al., 2014; Cutler et al., 1999). Together, this suggests the existence of a trade-off in which people in cosmopolitan cities may want to live apart yet consume together (Bakens et al., 2013).

In this paper, we study this potential trade-off in the impact that the presence of immigrants may have on local residential utility. To this aim, we first develop a simple spatial equilibrium model that explains intra-city house price differentials from access to immigrant-induced heterogeneous consumption goods and the ethnic diversity in population composition at the neighborhood level. The model is adapted from Accetturo et al. (2014), who assess the impact of ethnic population diversity on intra-city housing demand and mobility. In contrast to Accetturo et al. (2014), we model the utility derived from housing as dependent on the individual and potentially opposing preferences for ethnic heterogeneity among one's neighbors on the one hand and product variety in the neighborhood on the other hand. We assume that the latter effect captures the appreciation of the availability of a range of heterogeneous ethnic goods in the neighborhood, over and above the utility derived from the amounts consumed, for example because the very availability of these goods in the neighborhood contributes to a certain cosmopolitan flavor or lifestyle 1

Next, we conduct an empirical analysis to test for the impact of neighborhood-level externalities from the ethnic population composition versus the availability of heterogeneous ethnic goods on local house prices. Our case is the housing market in Amsterdam during the period 2006-2011. We combine micro data on house prices with information on the density and diversity of the immigrant population and ethnic restaurants to test for the existence of a trade-off between preferences for

\footnotetext{
${ }^{1}$ This idea that variety takes on some aspects of a public good, which enters as a direct argument in the utility function in addition to the well-known 'love of variety'-effect for consumption, was originally formulated in the working paper version of Dixit and Stiglitz (1975) that was later published in condensed form as the classic paper by Dixit and Stiglitz (1977). The public good effect was, however, no longer included in Dixit and Stiglitz (1977), which likely has contributed to the fact that this effect is ignored in most papers that use the 'love of variety'-effect. A noteworthy exception, however, is Ottaviano and Peri (2005) who formulate a separate term in their utility function that measures the utility loss ('disamenity') of having differentiated goods, which translates into ice-berg transaction costs in production. In contrast, we make no a priori assumptions about whether the public good character of ethnic consumption good varieties is positive or negative.
} 
amenities and neighbors. The case of Amsterdam fits the goal of our analysis well, in that Amsterdam is very much an ethnically diverse consumer city with sufficient spatial variation across residential areas in terms of the density and diversity of immigrants as well as immigrant-induced amenities. De Groot et al. (2010) and Vermeulen et al. (2016) show that land rents in Amsterdam are (much) higher than in the rest of the Netherlands, partly because of the rich amenities that make it an attractive residential area. Obviously, immigrants do not distribute randomly across neighborhoods and the effect of immigrant and restaurant density on house prices might (thus) very well be endogenous. We deal with this by using a quasi-experimental estimation method in the form of generalized propensity score (GPS) matching technique for continuous treatment variables following Hirano and Imbens (2004) $)^{2}$

In our analysis, density and diversity are continuous treatment variables that affect house prices depending on the treatment's intensity. Both Hirano and Imbens (2004) and Egger and Von Ehrlich (2013) show that the procedure of using GPS with multiple continuous endogenous treatments results in an unbiased estimate of the effect of the treatment variables (density and diversity of population and restaurants) on the outcome variable (house prices). We account for the fact that a trade-off between preferences for consuming and living together are non-linear in nature and may depend on spatial scale 3 We hypothesize that the effect of a neighborhood's population composition on residential utility matters most in the direct local environment of a house, while consumer amenities can more easily be enjoyed outside of the direct environment of the house (one can travel to go out for dinner).

Our focus on restaurants as a measure of consumer amenities serves two purposes. First, restaurants sell goods that need to be consumed locally. The kind of products supplied therefore reflect the taste of the local consumer (George and Waldfogel, 2006; Waldfogel, 2008; Mazzolari and Neumark, 2012). House prices in this local market, then, reflect the utility derived from these consumer goods. Second, restaurants can easily be differentiated by ethnicity. Very few products or services so clearly reflect ethnicity or country of origin as sushi restaurants or trattorias selling home-made pasta. ${ }^{4}$ The ethnic feature of the cuisine of the restaurant is a measure of horizontal product differentiation that focuses on differences in consumer tastes $5^{5}$

To our knowledge, we are the first to investigate the potential trade-off between utility derived from immigrant-induced consumer amenities and the residential population composition. We find evidence that supports the hypothesis that city dwellers prefer to live apart and consume together, and that these preferences lead to trade-offs that capitalize in house prices. Our results confirm that immigrant-induced (heterogeneous) consumer products create positive externalities that ameliorate the negative effect of the presence of immigrants on house prices. In addition, we find that house prices are higher in less diverse neighborhoods, all other things being equal. This especially holds for restaurant diversity which adds to the attractiveness of restaurant-dense areas.

The structure of the paper is as follows. In the next section, we develop our spatial equilibrium

\footnotetext{
${ }^{2}$ Examples of the empirical implementation of GPS matching for continuous treatment variables can be found in Fryges and Wagner (2008); Becker et al. (2012); Mitze (2014).

${ }^{3}$ One can imagine that the marginal effect of an increase in immigrant density on neighborhood attractiveness depends on the existing level of immigrant density. The same holds for the density of amenities: an additional restaurant in a neighborhood with many restaurants may have a different effect on the neighborhood's attractiveness than a new restaurant in a neighborhood with only a limited number of restaurants.

${ }^{4}$ Ethnic shops also arise in areas with many immigrants, but products sold in shops do not need to be consumed locally, and shops are much more difficult than restaurants to differentiate following an ethnic criterion.

${ }^{5}$ We are not able to distinguish between horizontal and vertical product differentiation. In the latter, the quality of restaurants based on, for example, price, is used (Berry and Waldfogel, 2010).
} 
model that captures the trade-off between a neighborhood's population composition and access to diversified consumer goods in determining house prices. In Section 3 we describe the estimation and inference of the multiple continuous treatments. We then describe the data in Section 4 and the spatial distribution of the treatment effects and house prices in Section 5 . Section 6 presents the estimation results, and Section 7 concludes.

\section{Theoretical Model}

We develop a simple spatial equilibrium model of an intra-city housing market where house price differentials across neighborhoods reflect spatial variation in the population composition and density as well as spatial variation in access to non-tradable heterogeneous consumption goods, such as restaurants. There are two types of individuals in the city, natives and immigrants, who maximize their utility through demand for housing $H$ and consumption goods $C$. The utility of the representative consumer living in neighborhood $d$ is modeled according to the following Cobb-Douglas utility function:

$$
U_{d}=C_{d}^{\alpha}\left(A_{d} H_{d}\right)^{1-\alpha} .
$$

The inflow of immigrants affects both the utility derived from housing and consumption goods. To model the impact of ethnic population diversity on intra-city housing demand, we adapt a spatial equilibrium model on the effects of immigration on intra-city house prices and mobility developed by Accetturo et al. (2014). In equation (1), the utility derived from housing depends on an externality $A$, which is a function of the local immigrant population $m$. In contrast to Accetturo et al. (2014), who assume that $A(m)$ is a general neighborhood amenity. We thus specify that local population externalities impact the demand for housing in a way that can be compared to the overall quality of living in a neighborhood. Variation in the population composition across neighborhoods thus leads to intra-city differences in utility derived from housing. We make no a priori assumptions about whether $A^{\prime}(m)$ is positive or negative.

To model the impact of ethnic population diversity on intra-city demand for consumption goods $C$, we assume that the aggregate consumption good $C$ in equation (1) is a composite of nontradable heterogeneous goods, that are differentiated by ethnic characteristics $i$. In other words, the variety that is produced by an individual depends on her ethnicity, and the consumption goods supplied in neighborhood $d$ thus depend on both the demand and the population composition of that neighborhood. Typical examples of non-tradeable ethnic varieties of consumption goods that may vary across neighborhoods are ethnic restaurants, specialty food, entertainment or hair stylists that are supplied in different varieties by people of different cultures (cf. Ottaviano and Peri, 2005). To this aim, we explicitly model the demand for diversified goods under the assumption of a 'love for variety', as introduced by Dixit and Stiglitz (1975) and used in Ottaviano and Peri (2005). Hence, we define a sub-utility of $C$ in each neighborhood that follows a Constant Elasticity of Substitution (CES) function to capture the variety structure described above:

$$
C_{d}=\left[\sum_{i=1}^{n_{d}} x_{i}^{\rho}\right]^{\frac{1}{\rho}} n_{d}^{\delta I_{m}}, \quad \text { with } \quad 0<\rho<1 .
$$

In this specification, the utility derived from consuming non-tradable heterogeneous goods consists 
not only of a traditional 'love of variety'effect (which is present if $\frac{1}{\rho}-1>0$ ), but also of a public good effect $(\delta)$. The first term on the right-hand side of equation (2) is the appreciation by individual agents of consuming a variety of heterogeneous ethnic goods in the neighborhood. A neighborhood has a total of $n_{d}$ neighborhood-specific varieties. The total number of varieties in the city is exogenously given, but, as noted before, the number of varieties in each neighborhood depends on the population composition of that neighborhood. If the varieties are imperfect substitutes, there is a positive return to diversity if $(1 / \rho-1)+\delta>0$.

The second term on the right-hand side of equation (2) is the utility that individuals obtain from the availability of a range of heterogeneous ethnic goods in the neighborhood, over and above the effect through the amounts consumed. "This may reflect the desirability of accommodating a sudden future change of tastes, or of retaining one's identity by consuming products different from those consumed by one's neighbors, or some such consideration" (Dixit and Stiglitz, 1975). As noted before, in the context of our analysis, this idea that variety takes on some aspects of a public good may reflect the fact that the availability of diversified goods, like ethnic restaurants or specialty food shops, in itself contributes to a certain cosmopolitan flavor in a neighborhood (viz. it has an existence value). We make no a priori assumptions about whether the public good character of ethnic consumption good varieties is positive or negative. If $\delta$ is larger than zero, diversity is considered a public good, while diversity is considered a public bad if $\delta$ is smaller than zero. Total individual income $Y$ is independent of location $d$ and consists of wages ${ }^{6}$ There is homogeneity in production structures across the different goods resulting in $p_{i}=p$ for each $i$. The budget constraint faced by a representative individual is as follows:

$$
Y=q_{d} C_{d}+r_{d} H_{d}
$$

where $q_{d}$ is the price index of consumption goods in neighborhood $d$, and $r_{d}$ is the price of housing in neighborhood $d$. Standard two stage utility maximization leads to the following demand functions for a representative individual living in neighborhood $d$ :

$$
\begin{aligned}
H_{d} & =(1-\alpha) \frac{Y}{r_{d}}, \text { and } \\
C_{d} & =\alpha \frac{Y}{q_{d}} .
\end{aligned}
$$

In the second stage, we maximize equation (2) subject to $\sum p_{i} x_{i} \leq \alpha Y$. This results in:

$$
x_{i}=\alpha Y p_{i}^{-\varepsilon} q_{d}^{\varepsilon-1} n_{d}^{\delta I_{m}(\varepsilon-1)},
$$

\footnotetext{
${ }^{6}$ We assume that the spatial scope of production externalities that affect wages is substantially larger than the externalities that we study here and that for that reason we can safely neglect production externalities in the analysis.
} 
in which $\varepsilon=1 /(1-\rho)$ and is thus equal to the price elasticity of demand for varieties, and the corresponding price index $q_{d}$ which is:

$$
q_{d}=\left[\sum_{i=1}^{n_{d}} p_{i}^{1-\varepsilon}\right]^{\frac{1}{1-\varepsilon}} n_{d}^{-\delta I_{m}}
$$

Equation (6b) shows that because the public good-aspect of diversified consumption goods differs across neighborhoods $d$, the price index differs across neighborhoods.

We define the total (exogenously given) number of natives in the city as $N$, and the (endogenous) share of natives in neighborhood 1 as $\lambda$. Immigrant income is assumed to equal $\sigma Y$, with $0<\sigma<1$. The aggregate demand for housing in each neighborhood is then given by:

$$
\begin{aligned}
H_{1}^{D} & =\lambda N \frac{(1-\alpha) Y}{r_{1}}, \text { and } \\
H_{2}^{D} & =[(1-\lambda) N+\sigma m] \frac{(1-\alpha) Y}{r_{2}}
\end{aligned}
$$

We assume that the housing supply in each neighborhood is given by:

$$
H_{d}^{S}=\psi_{d} r_{d}^{\gamma}
$$

where $\gamma(\geq 0)$ is the price elasticity of housing supply in neighborhood $d$. In the special case in which $\gamma=0$, supply of housing is vertical.7

Equilibrium prices in the housing market are determined by equalizing the housing supply function to the neighborhood-specific housing demand functions as given in equations (7) and (8). For neighborhood 1, the equilibrium price is:

$$
r_{1}^{*}=\left[\lambda N \frac{(1-\alpha) Y}{\psi_{1}}\right]^{\frac{1}{1+\gamma}} .
$$

The equilibrium price for neighborhood 2 is:

$$
r_{2}^{*}=\left[[(1-\lambda) N+\sigma m] \frac{(1-\alpha) Y}{\psi_{2}}\right]^{\frac{1}{1+\gamma}}
$$

To preserve full analytical tractability of the model and guidance of the empirical analysis, we follow Accetturo et al. (2014) in assuming that natives can move freely and without costs across neighborhoods, but not outside the city. In contrast, the immigrant population $m$ is exogenously

\footnotetext{
${ }^{7}$ If $\gamma=0$, housing supply is fixed, so that an increase (decrease) of natives in a neighborhood leads to a higher (lower) population density. The key results of the model do not crucially depend on this assumption. See result 4 in Accetturo et al. (2014).
} 
concentrated in neighborhood 2.8

Consequently, the local population externality in neighborhood $1\left(A_{1}\right)$ is defined as $A_{1}(m)=A$, while $A_{2}(m)=A(m)$. We make no a priori assumptions about whether $A_{1}$ is valued higher than $A_{2}$ and, as noted before, whether $A_{2}^{\prime}(m)$ is positive or negative. Another consequence of the assumption that all immigrants concentrate in neighborhood 2 is that there is no public good effect of diversified products in neighborhood $1\left(I_{m}=0\right)$ while the public good effect in neigborhood 2 equals $n_{d}^{\delta}\left(I_{m}=1\right), 9$

Combining equations (5) and (6b) and using symmetry of varieties within regions, we can derive $C$ as:

$$
\begin{aligned}
& C_{1}=n_{1}^{\frac{1}{\rho}-1} \alpha Y p^{-1} \\
& C_{2}=n_{2}^{\frac{1}{\rho}-1+\delta} \alpha Y p^{-1} .
\end{aligned}
$$

Inserting these values and equations (4), (10) and (11) into the utility function for natives in the two neigborhoods and putting their respective utility values equal, allows us to solve for $\lambda$, viz. the share of natives in neighborhood 1 in equilibrium:

$$
\lambda=\frac{N+\sigma m}{N} \frac{\psi_{1}\left(n_{1}^{\left(\frac{1}{\rho}-1\right) \frac{\alpha}{(1-\alpha)}} A_{1}\right)^{1+\gamma}}{\psi_{1}\left(n_{1}^{\left(\frac{1}{\rho}-1\right) \frac{\alpha}{(1-\alpha)}} A_{1}\right)^{1+\gamma}+\psi_{2}\left(A_{2}(m) n_{2}^{\left(\frac{1}{\rho}-1+\delta\right) \frac{\alpha}{1-\alpha}}\right)^{1+\gamma}} .
$$

From equation (13), it follows that the share of natives in neighborhood 1 depends on size and income of the city's immigrant population (first term on the right-hand side), the supply of housing in both neighborhoods (driven by $\psi$ ), and appreciation of amenities in both neighborhoods (captured by $A$ and $n$ ). As regards local neighborhood amenities, the share of natives in neighborhood 1 decreases with an increasing valuation of population externalities in neighborhood 2 relative to neighborhood 1, an increasing number of ethnic consumption good varieties $\left(n_{2}\right)$ and an increasing appreciation of the public good effect $(\delta)$ of having heterogeneous ethnic goods in neighborhood 2.

Ultimately, in our empirical analysis we aim to assess the joint impact of immigrant-induced population externalities and amenities on intra-city house prices, by testing for a potential trade-off in which city dwellers prefer to live apart yet consume together. To this aim we need to identify in our model the effect of intra-city variation in the number of immigrants $m$ on intra-city house price differentials. Therefore, we first calculate the average weighted house prices in the city from equations $(9)-(11)$, using the share of natives in neighborhood 1 in equilibrium from equation (13):

\footnotetext{
${ }^{8}$ As is shown in the empirical analysis, the location of immigrants is much more restricted, for example, because of dependency on social housing, than that of the native population.

${ }^{9}$ We thus assume that there is no public good effect of ethnic restaurants in neighborhood 1 because all ethnic restaurants are located in neighborhood 2 because that is where the immigrants live. This implies that the location of ethnic restaurants coincides with the residential location immigrants. In reality, this does not need to be the case. In the empirical part of this paper, we show that this assumption is not necessarily confirmed by our data as locations with a higher restaurant density have a lower residential density. However, restaurants are more diverse in neighborhoods with more immigrants.
} 


$$
\begin{aligned}
\bar{r}^{*} & =\frac{[(N+\sigma m)(1-\alpha) Y]^{\frac{1}{1+\gamma}}}{\left(\psi_{1} \omega(m)\right)^{\frac{\gamma}{1+\gamma}}+\left(\psi_{2}(1-\omega(m))\right)^{\frac{\gamma}{1+\gamma}}}, \text { with } \\
\omega(m) & =\frac{\psi_{1}\left(n_{1}^{\left(\frac{1}{\rho}-1\right) \frac{\alpha}{(1-\alpha)}} A_{1}\right)^{1+\gamma}}{\psi_{1}\left(n_{1}^{\left(\frac{1}{\rho}-1\right) \frac{\alpha}{(1-\alpha)}} A_{1}\right)^{1+\gamma}+\psi_{2}\left(A_{2}(m) n_{2}^{\left(\frac{1}{\rho}-1+\delta\right) \frac{\alpha}{1-\alpha}}\right)^{1+\gamma}} .
\end{aligned}
$$

The average house price in the city thus depends on population size, income (distribution), price elasticity of housing supply and appreciation of the various local amenities. Using equations (10) and (11), we can also determine the equilibrium relative house prices across neighborhoods:

$$
\frac{r_{1}^{*}}{r_{2}^{*}}=\left(\frac{\omega \psi_{2}}{(1-\omega) \psi_{1}}\right)^{\frac{1}{1+\gamma}}
$$

With these results, we can now identify the impact of immigrants and distinguish several effects. First, according to equation $(13)$, an increase in immigrants in neighborhood 2 increases the average price of housing in the entire city (through a demand effect, which is stronger the more inelastic the supply of housing). Second, assuming that an increase in immigrants positively affects $n_{2}$, more immigrants increase both the total price of housing (equation 13 ) as well as the relative price of housing in neighborhood 2 (equation 14 provided that the love for diversity effect $\left(\frac{1}{\rho}-1\right.$ ) and the public good effect (captured by $\delta$ ) are jointly positive (or in other words: as long as the potentially negative public good effect is not too strong). Third, both the total price of housing (equation 13) as well as the relative price of housing (equation 14), positively depend on $A_{2}$ as long as $A_{2}$ is increasing in the number of immigrants $(m)$.

These theoretical findings guide our empirical analysis by showing that the changes in relative house prices differentials between neighborhoods in response to an increasing immigrant population in the city are determined by utility derived from changes in local population externalities and the public good character of ethnic consumption good varieties. Furthermore, there is a potential trade-off between the two sources of immigrant induced amenity effects: A negative (positive) utility effect of an increase in the ethnic population composition may be attenuated (reinforced) by a positive (negative) utility effect of an increase in available ethnic consumption good varieties. In the remainder of the paper, we take the insights to the data, to test for the (potentially opposing) effects of ethnic diversity in terms of population composition and consumption good variety on house prices.

\section{Identification Strategy}

In order to isolate the effects of immigrants and (the availability of) ethnic products on house prices, we compare the prices (the outcome) of houses that differ in terms of the density and diversity of the local immigrant population and restaurants (the treatment) in the houses' local environment, but that have similar house and neighborhood characteristics. The underlying assumption of this 
matching procedure is that the conditional probability of assignment to a particular treatment intensity given the observed covariates $X$, i.e., the generalized propensity score (GPS), can be used to remove any biases associated with these covariates and will result in an unbiased estimate of the causal effect of a treatment variable $T$ on an outcome variable $Y$ (Rosenbaum and Rubin, 1983). Because our treatment variables are continuous, the effect of the treatment variables on the outcome variables are evaluated along the distribution of treatment intensities ${ }^{10}$ This gives us the average treatment effect on the treated (ATET).

Hirano and Imbens (2004) show that the GPS can be used for continuous treatments based on the assumption of weak unconfoundedness. Unconfoundedness implies the independence of the treatment variable $T$ and the outcome $Y$ (Rosenbaum and Rubin, 1983), while weak unconfoundedness is satisfied if the treatment and outcome are independent conditional on the observed covariates, $X$. The conditional density of the treatments, $g$, subject to the treatment intensity $T$ given the covariates $X$ is defined as follows:

$$
g(t, x)=f_{T \mid X}(t \mid x),
$$

and the GPS $(G)$ is defined as $G=g(T, X)$. This means that within strata of the same value of $g(t, x)$, the probability of receiving a particular treatment intensity does not depend on the covariates. Controlling for the GPS then removes the bias associated with the covariates.

The approach of Hirano and Imbens can be modified for multiple continuous treatments following Egger and Von Ehrlich (2013), who show that the bias-removing properties of the singletreatment GPS also holds for multiple endogenous treatments. If we define the number of continuous endogenous treatments as $m=(1,2, \ldots, M)$, the joint density of $\left(t_{1}, t_{2}, \ldots, t_{M}\right)$ given $X$ is equal to equation (16), and the GPS is defined as:

$$
G=g(T, X), \quad X_{i} \perp 1\left\{T_{m}=t_{m}, \forall m\right\} \mid g(t, X)
$$

Controlling for the GPS in equation (17) gives the probability of the treatment being equal to some potential treatment combination $(t)$ conditional on the covariates $(X)$.

The dose-response function for multiple treatment effects is estimated in three stages (following Hirano and Imbens, 2004). In the first step, the conditional distribution of the treatments given the covariates is modeled. A multivariate normal distribution of the treatment given the covariates is estimated by maximum likelihood using equation (17), given by:

$$
T_{i} \mid X_{i} \sim N\left(\beta_{0}+\beta_{1}^{\prime} X_{i}, \operatorname{cov}\left(t_{m}, t_{m}^{\prime}\right)\right)
$$

and using equation $(18)$ the estimated GPS for the multiple treatment is:

$$
\hat{G}_{i}=\frac{1}{\sqrt{(2 \pi)^{M}|\Sigma|}} \exp \left(-\frac{1}{2}\left(x_{i}-\mu\right)^{\prime-1}\left(x_{i}-\mu\right)\right),
$$

where $\Sigma$ is the variance-covariance matrix of the treatments from equation (18).

\footnotetext{
${ }^{10}$ In this section, we only discuss the basic differences between a binary treatment and continuous treatment. For more information, we refer to Rosenbaum and Rubin (1983); Hirano and Imbens (2004).
} 
In the second stage, the conditional expectation of $Y_{i}$ given the treatments $\left(T_{m}\right)$, and $\hat{G}$ is estimated using ordinary least squares (OLS). We use a third-order polynomial approximation $(d)$ with appropriate pairwise interactions among treatments to allow for non-linearities in the (interacted) treatment effects which leads to the following:

$$
\begin{aligned}
E\left[Y_{i} \mid T_{m}, G^{d}\right]= & \alpha_{0}+\sum_{d=1}^{3}\left\{\sum _ { m = 1 } ^ { M } \left(\alpha_{1, m d} T_{m}^{d}+\alpha_{2, m d} T_{m}^{d} G^{d}+\right.\right. \\
& \left.\left.\sum_{n \geq m}^{M-1}\left(\beta_{1, n d} T_{m}^{d} T_{n+1}^{d}+\beta_{2, n d} T_{m}^{d} T_{n+1}^{d} G^{d}\right)\right)+\alpha_{3} R^{d}\right\}
\end{aligned}
$$

where the interactions contribute to the trade-offs between the different treatments $m$. Bootstrap methods can be used to calculate the standard errors and confidence intervals of the dose-response function.

In the final stage, the average potential outcome at treatment level combination $t$ is estimated given the estimated parameters from equation $(20)$ :

$$
\begin{aligned}
E\left[\widehat{Y\left(T_{m}\right)}\right]= & \frac{1}{N} \sum_{i=1}^{N}\left[\alpha_{0}+\sum_{d=1}^{3}\left\{\sum _ { m = 1 } ^ { M } \left(\alpha_{1, m d} t_{m}^{d}+\alpha_{2, m d} t_{m}^{d} G^{d}+\right.\right.\right. \\
& \left.\left.\left.\sum_{n \geq m}^{M-1}\left(\beta_{1, n d} t_{m}^{d} t_{n+1}^{d}+\beta_{2, n d} t_{m}^{d} t_{n+1}^{d} G^{d}\right)\right)+\alpha_{3} G^{d}\right\}\right],
\end{aligned}
$$

where the ATET is estimated at different treatment intensities to obtain the dose-response function, and $N$ is the number of observations in the data set.

For our purpose, this identification strategy has a number of advantages. With propensity score matching, only comparable subjects are compared and the intensity of the treatment is taken into consideration (which would not be the case with linear OLS estimation). By carefully selecting the covariates, we can avoid the endogeneity bias, i.e., the causality between immigrant and restaurant density or diversity and house prices running both ways. Another important reason to carefully select the covariates in this estimation is that the performance of the GPS matching depends on the balancing properties of the covariates and the assumption of the normality of the distribution of the treatments conditional on the covariates. There is, however, very little research of the basis on which to select the covariates in propensity score models. Using simulations for the standard binary matching procedure in life sciences, Rubin and Thomas (1996) and Brookhart et al. (2006) show that all variables that explain the outcome variable should be included, regardless of whether these variables explain exposure. This selection strategy reduces the variance of the estimated treatment effect without increasing the bias. Covariates that only explain the treatment but not the outcome increase the variance of the estimated treatment effect without decreasing the bias. Generally speaking, variables that explain the outcome are usually also related to the exposure variable (Brookhart et al., 2006), which is the case in our analysis.

For the GPS to obtain unbiased estimates of the dose-response function, the covariates need 
to be normally distributed. We use the Henze-Zirkler test for multivariate normality (Henze and Zirkler, 1990) to test for the normality of the errors in equation (18). An adequate balancing score is obtained if the mean value of the covariates at a particular value in some treatment interval is not significantly different from the mean value of the covariates outside of that treatment interval. For a full description of the testing of the balancing properties, we refer to Hirano and Imbens (2004). Calculating the balancing of the GPS in the case of multiple treatments is rather cumbersome, and we rely on single-treatment calculations and assume that treatments are independent.

Applying quasi-experimential comparison group designs to infer causal relationships in regional science and geography is promising, but the fact that data are spatial in nature complicates the applicability and usefulness of quasi-experimental comparisons (Feser, 2013; Mitze, 2014). Especially on a more aggregate level, matching identical spatial entities proves challenging given the heterogeneity of spatial entities such as regions, cities or neighborhoods. Mitze (2014) shows that finding spatial 'statistical twins' is difficult because treatments are not likely to be spatially independent of the characteristics of regions. As we describe below, our data overcome some of the more general spatial drawbacks. We use the exact location and local environment of individual dwellings and we are therefore not impeded by spatial administrative boundaries or larger spatial patterns that are evident in neighborhoods or city districts.

\section{Data and Operationalisation}

We construct a unique data set with micro-data on house prices in Amsterdam for sales transactions during the period 2006-2011. The data set can be divided into three parts. The first part contains the data on individual house transactions, and includes georeferenced information that can be used to obtain spatial coordinates. The housing data are provided by the Dutch Association of Real Estate Agents (NVM). The second part of the data set contains sociodemographic characteristics at the 6-digit ZIP code level. Amsterdam consists of about 17,000 6-digit ZIP code areas, each comprising approximately 25 residential dwellings on average. The third part of the data set contains information on restaurants, with georeferenced information available for each outlet. The 6-digit ZIP code level data and the data on restaurants are provided by the Department of Research, Information, and Statistics (OIS) of the Municipality of Amsterdam.

From the data set we construct our dependent variable as the house price per square meter livong space in constant 2008 euros ${ }^{11}$ Other variables that are included are the number of rooms, the presence of a garden, the type of dwelling (house or apartment), and the year of the transaction. To control for the characteristics of the local neighborhood of the house, we include the share of owneroccupied dwellings and the share of social rent dwellings (with commercial rent as the reference category) among the houses within the direct surroundings of the dwelling in the 6-digit ZIP code area. 12 This variable gives an indication of income levels. Data on accessibility to amenities is included, such as the distance to the central railway station, the distance to the nearest metro station, a dummy for location within the ring road (the A10 highway), and the distance to the ten

\footnotetext{
${ }^{11}$ In order to exclude extremely small or large houses, we restrict the sample to houses priced between $€ 30,000$ and $€ 4,500,000$ and a floor area between $30 \mathrm{~m}^{2}$ and $475 \mathrm{~m}^{2}$.

12 Because we do not have data on income, the share of social rent is included. It turns out that the share of the 6-digit ZIP code population that is dependent on social welfare are highly correlated with the number of houses with social rent at the 6-digit ZIP code level. Because the data on social rent are available for all observations, this variable is included.
} 
main tourist attractions in the city. ${ }^{13}$

Our main variables of interest are the density and diversity of immigrants and restaurants. The country of birth of one's parents is used to determine ethnicity (with the maternal side being the leading determinant). An immigrant is defined as anybody for whom at least one parent was born outside of the Netherlands 14 To calculate the diversity among immigrants, a distinction is made between Western and non-Western immigrants. Immigrants from Europe, North America, Australia, New Zealand, Japan, and Indonesia ${ }^{15}$ are Western immigrants. We further categorize the non-Western immigrants into five groups: Turks, Moroccans, Surinamese, Antillean/Aruban, and other non-Western.

For restaurant density and diversity, we use the country of origin of the type of cuisine served by the restaurants. For each restaurant, the name and location are available in the data set. With this information, each restaurant was checked to determine the ethnicity of the cuisine based on: (i) the name of the establishment, (ii) the characteristics found in Chamber of Commerce data on the Internet, or (iii) the establishment's appearance on Google Streetview. Paradoxically, although a very typical Dutch cuisine exists, it is difficult to find in restaurants. It is rather blended with Belgian, French, and Italian dishes. Additionally, many Belgian, French, or Italian restaurants are Dutch-owned. Therefore, it is difficult to distinguish between Dutch, Belgian, French, and Italian cuisine, and all of these are considered Dutch or native. The different ethnic groups of restaurants used in the analysis are European, Middle-Eastern/Arabic, African, Asian, and American.

We introduce the following notation to formally define the spatial dimension of the measures used in the empirical analysis. The location of individual homeowner $i$, who buys a property located at location $j$, is defined in terms of coordinate pairs $\left(j_{x}, j_{y}\right){ }^{16}$ We identify four key aspects of the local environment $j^{+}$for individual $i$, where the local environment $j^{+}$is defined as a circular area with a radius of 250 meters for the population around location $\left(j_{x}, j_{y}\right)$ and a radius of 1kilometer for restaurants around location $\left(j_{x}, j_{y}\right)$. We thus assume that the spatial scale at which immigrant density impacts consumer utility differs from the spatial scale at which restaurant density impacts utility. The larger the local environment used in the calculation of equations $(22)$ and (23), the smaller the variation in the observed density and the more closely each observation reflects the overall density of Amsterdam. Although 250 and 1000 meters are arbitrarily chosen, a larger radius decreases the standard deviation of the distribution for each variable. To maintain identification based on variation in the data, we therefore choose 250 and 1000 meters as the spatial scales.

The first two aspects of the local environment are immigrant and restaurant density. Density is measured as the total immigrant population or number of restaurants in the local environment $j^{+}$of individual $i$ relative to the density in Amsterdam as a whole. For immigrant density we calculate:

$$
s p_{i j}=\frac{p_{j_{p}^{+}}}{P}
$$

\footnotetext{
${ }^{13}$ The ten main tourist attractions are based on visitor numbers. We use total distance from the dwelling to the ten attractions. The ten tourist attractions used are the Rijksmuseum, Van Gogh Museum, Anne Frank Huis, Artis Zoo, Stedelijk Museum, Madame Tussauds, Heineken Experience, Nemo Science Center, Hermitage, and Venustempel Museum.

${ }^{14}$ This is the commonly used definition in the Netherlands.

${ }^{15}$ Indonesia is a former Dutch colony, and many Indonesians have the Dutch nationality. For both Indonesians and Japanese, the cultural distance with the Dutch is smal compared to other non-Western groups.

${ }^{16}$ We explicitly distinguish $i$ and $j$ because different individuals (or properties) $i$ may share the same location $j$ in our two-dimensional representation of space, for instance, in the case of apartment buildings.
} 
with $p$ the immigrant density around the location of individual $i$, and $P$ the immigrant population of Amsterdam per square kilometer ${ }^{17}$ For ethnic restaurants we calculate:

$$
s a_{i j}=\frac{a_{j_{a}^{+}}}{A},
$$

with $a$ the restaurant density per inhabitant around the location of individual $i$, and $A$ the restaurant density in Amsterdam per inhabitant.

In addition to the density of immigrants and restaurants we look at their diversity, labeled d. Diversity is defined using the Hirschman-Herfindahl index. We first measure the presence of immigrants (or restaurants) representing culture $c=(1,2, \ldots, C)$ in the local environment $j^{+}$of individual $i$, which is measured as the number of immigrants (or restaurants) representing culture $c$ as a fraction of the total immigrant population (or the number of restaurants) in the local environment:

$$
\begin{aligned}
& p_{i j}^{c}=\frac{p_{j_{p}^{+}}^{c}}{\sum_{c} p_{j_{p}^{+}}^{c}}, \text { and } \\
& a_{i j}^{c}=\frac{a_{j_{a}^{+}}^{c}}{\sum_{c} a_{j_{a}^{+}}^{c}} .
\end{aligned}
$$

Because population measures are only available at the aggregate 6-digit ZIP code level (while restaurants are available at the exact location), we use the centroids of postcode- 6 areas, properly weighted to account for the locations of houses within those areas, to determine the 6-digit ZIP code areas that fall within the circle that defines the local environment $j^{+}$of individual $i$.

The diversity index measures the diversity of the immigrant population and restaurants in the local environment $j^{+}$of individual $i$ located at $j$ :

$$
\begin{aligned}
& d p_{i j}= 1-\frac{\sum_{c=1}^{C}\left(p_{i j}^{c}\right)^{2}-1 / C}{1-1 / C}, \text { and } \\
& d a_{i j}=1-\frac{\sum_{c=1}^{C}\left(a_{i j}^{c}\right)^{2}-1 / C}{1-1 / C} .
\end{aligned}
$$

The diversity measure is a function of the immigrant and restaurant shares defined in equations (24) and (25), respectively, and is defined over the closed interval [0,1], where a higher value reflects a larger diversity in the immigrant population or restaurant diversity in terms of culture.

Analogously to the density measure, we use the relative diversity index, i.e., the diversity relative to the overall diversity of the immigrant population and restaurant diversity in Amsterdam. Because of this scaling, the distribution of the measures is not normally distributed around one, which would

\footnotetext{
${ }^{17}$ We rescale the outcome to obtain the density of immigrants per square kilometer.
} 
have been the case if we had used the measures relative to the density or diversity in the sample.

With these different measures, the dataset contains information about the salient characteristics of the local environment around each house, both in terms of the immigrant composition and in terms of access to ethnically diverse food outlets. A summary of descriptives can be found in Tables 1 and 2. The spatial distribution of the treatments, specifically the treatment intensities, and the joint spatial occurrence of multiple treatment intensities are discussed below.

$\langle$ Tables 1 and 2 about here >

\section{Distribution of Treatments and Outcome}

The outcome variable for the trade-off between immigrant and restaurant density is the house price per square meter of living space. Figure 1 shows the spatial distribution of house prices in Amsterdam ${ }^{18}$ The highest prices per square meter are in the city center around the canals, in the area around the Vondelpark and in the south. These are the areas with large and historic buildings and dwellings. Generally, the pattern of high house prices in Amsterdam is identical to the spatial pattern common to large (European) cities with a historic city center. There is a more or less abrupt transition from high to low prices per square meter to the west, north and south-east of the city center. The transition roughly coincides with locations within or outside of the A10 highway ring road. To the north of the city center, there is a waterway that also serves as a general boundary for high house prices. The share of social housing in the total housing stock is also relatively high in the areas outside of the ring road and in the north. To the east, the average house prices on the newly developed island of IJburg are close to or higher than the city average. The disconnected area in the south-east was developed in the 1960s and is, more than any other area in the city, home to a large concentration of non-Western immigrants. The harbor of Amsterdam is located to the north-west, which is excluded from the analysis because of the low number of residential houses in this area.

\section{$\langle$ Figure 1 about here 〉}

Figure 2 shows the immigrant and restaurant density in the local surroundings of the houses in our data. The density is measured relative to the density in Amsterdam as a whole. If the density is close to one, the density of the local area is close to the overall density in Amsterdam. Values below one indicate below-average density and values above one indicate above average density. The spatial distribution of the density of immigrants and restaurants is mainly determined by Amsterdam's built environment, city planning, and the characteristics of the housing stock. The immigrant density is highest just inside and around the A10 highway ring road. The city center is characterized by relatively large, expensive houses, while the areas near the city boundaries are characterized by larger, less expensive houses. For both these areas, the population density is lower than average. Although immigrants are also clustered towards the south-eastern and western parts of the city, we only find small pockets of above-average immigrant density. This is due to the fact that population density is relatively low in these areas and because many immigrants live in clustered social housing (just as owner-occupied houses are clustered). During the period covered

\footnotetext{
${ }^{18}$ All observations are plotted in rasters of 3,500 square meters (59 by 59 meters). The value of a raster indicates the average house price of all observations in that raster.
} 
by our research (2006 to 2011) immigrant density increased somewhat. By 2011 more areas had an above-average population density because both the overall population density of Amsterdam and the median immigrant density in the local areas increased between 2006 and 2011.

\section{$\langle$ Figure 2 about here $\rangle$}

The restaurant density results show a concentric pattern from the city center: the concentration of restaurants decreases further away from the city center towards the more residential areas of the city. The clustering of restaurants in the city center is also related to the fact that the city center is the main tourist area, which increases the demand for restaurants in that part of the city.

Between 2006 and 2011, the distribution of ethnic restaurants in the city became somewhat less equal. The density of ethnic restaurants in Amsterdam decreased when the local restaurant density decreased during the Great Recession (starting in 2008) and increased again in 2011, which shows the sensitivity of consumer goods to the economic business cycle.

Figure 3 shows the distribution of the immigrant and restaurant diversity in Amsterdam. Just like density, the diversity is measured relative to the diversity in Amsterdam as a whole. If the diversity is close to one, the diversity of the local area is close to the overall diversity in Amsterdam. Values below one indicate below-average diversity and values above one indicate above average diversity. Generally, immigrant diversity is higher farther away from the city center. Both the city center and the south-east have low levels of immigrant diversity, the city center because of relatively low immigrant density and the south-east because of a relative homogeneous, non-Western immigrant population ${ }^{19}$ Generally, the areas with low immigrant diversity are also the areas with the highest house prices in Figure 1. However, the lowest house prices are not in the areas with the highest levels of population diversity. There are two pockets with high levels of population diversity inside the highway ring road, toward the west and east sides, and these areas have average to above-average house prices. There was no large change in the spatial distribution of diversity between 2006 and 2011. The immigrant diversity both in the local areas and in Amsterdam as a whole have remained the same between 2006 and 2011.

\section{$\langle$ Figure 3 about here 〉}

Restaurant diversity is generally higher in areas with relatively lower levels of restaurant density, specifically to the east and west of the city center. The city center remains the area with a restaurant composition that most resembles the average in Amsterdam. The diversity observed at the western boundary of the city can be ascribed to the fact that an area with a few restaurants that have different ethnic origins exhibits a relatively high level of diversity, while in an area with many restaurants, fluctuations in the number of restaurants of different ethnic backgrounds have a smaller impact on the calculated diversity measure. The diversity of restaurants remained more or less stable between 2006 and 2011, while the diversity of restaurants in Amsterdam in general fluctuated with the density of restaurants; diversity decreased around 2008 and increased after the economic crisis.

The various maps provided in this section give some indication of the correlation between the different treatments. To elucidate the joint distribution of treatment intensities for immigrant density and restaurant density and diversity, Figures 4 and 5 show their spatial distribution. A darker

\footnotetext{
${ }^{19}$ The number of different ethnic groups is actually high in the south-east, but because we define other non-Western immigrants as one group, this area is rather homogeneous.
} 
hexagon signifies a higher number of observations around a treatment intensity. The majority of the observations in our data lie between a treatment intensity of 1 and 5 for immigrant density, between a treatment intensity of 0.9 and 1 for immigrant diversity, and below a treatment intensity of 1 for restaurants. Table 3 displays the correlation coefficients between all the treatments. The correlation between immigrant and restaurant density is negative and statistically significant (the coefficient is -0.14), which indicates that areas with many immigrants generally have few restaurants.

Table 3 also shows that restaurants are more diverse in areas with more immigrants. The positive relationship between restaurant diversity and immigrant density is not investigated in this paper, but used as an assumption. The statistically significant correlation points towards the fact that immigrant-induced, diverse, amenities arise with the presence of immigrants, because of a supply as well as demand effect of immigrants of ethnic goods and services. The data also reveals a positive correlation between restaurant density and diversity indicating that areas with a higher restaurant density on average have a higher diversity of restaurants. The same holds for immigrant diversity.

\section{$\langle$ Figure 4 and 5 about here $\rangle$ \\ $\langle$ Table 3 about here >}

\section{Results}

We first discuss the conditional treatment effects of the multivariate estimation for each treatment. Then the different normality and matching tests for the GPS correction following the three stages of the GPS estimation are discussed. We subsequently investigate whether there is a trade-off between people consuming together yet living apart. To this end, we estimate the trade-off between the treatment intensities of immigrant density and restaurant density, conditional on the diversity of immigrants and restaurants from the multivariate estimation, and the trade-off between immigrant density and restaurant diversity, conditional on the density of restaurants and the diversity of immigrants from the multivariate estimation 20

\subsection{Multivariate Results}

Because the treatment intensity of population and restaurant density and diversity is not randomly distributed across Amsterdam, a selection equation that includes the covariates is estimated in the first stage. The results of the conditional treatments from the selection equations are given in Table 4. Except for the garden dummy included in the immigrant density and diversity calculations and the distance to the top ten tourist attractions for the restaurant diversity calculations, all variables are statistically significant. The coefficients for dwelling characteristics all have the expected sign, with lower immigrant density in areas with larger houses. Immigrant density is higher in areas with more social housing and lower in areas with more owner-occupied houses (compared to commercial rent). An explanation for this result is the fact that social housing is generally allocated to apartments, not houses, and apartments increase population density. Another reason may be that

\footnotetext{
${ }^{20}$ We modified R scripts originally written for single continuous treatments by Raymond Florax, Anita Yadavalli, and Ying Liu, at Purdue University. The script is available upon request.
} 
immigrants tend to have larger families and have a higher tendency to rent in the areas with social housing. The neighborhood characteristics show that restaurant density is lower farther away from the central places in the city, i.e., further away from the city center railway station, metro stations, and the main tourist attractions which are all located within the A10 highway ring road. These covariates explain about 53 percent of the variation in immigrant density and 81 percent of the variation in restaurant density.

\section{$\langle$ Table 4 about here 〉}

In accordance with the immigrant density results, population diversity is lower in areas with larger houses and in areas closer to the city center. Population diversity is also higher in areas with more social housing and owner-occupied dwellings (compared to commercial rent). Renting a house in the commercial sector is the most expensive option for housing in Amsterdam, which may be an explanation for these results. High-income residents select into locations with commercial rent, and high-income residents are likely to be a relatively ethnically homogeneous group of people. Population density has a positive correlation with immigrant and restaurant diversity, indicating that higher density increases the odds of higher diversity and that there is a correlation between the diversity of the local population and the heterogeneity of local consumer demand, as proposed by, among others, Waldfogel (2008). Restaurant diversity is lower in the central areas of the city near the central railway station, metro stations, and the main tourist attractions, while restaurant diversity is higher outside of the highway ring road. Higher restaurant density is thus not a prerequisite for higher restaurant diversity.

The $R^{2}$-values of the immigrant and restaurant diversity estimations are relatively low, 25 percent and 37 percent, respectively. Although the spatial distribution of the treatment intensity of restaurant and immigrant diversity does not indicate the nature of the omitted variables, there is likely an underlying pattern explaining restaurant and immigrant diversity that we cannot perfectly capture with our data. Restaurant diversity might also be related to market factors such as competition and quality, while immigrant diversity might relate to other spatial aspects, that we do not observe.

In the second stage, we estimate the conditional expected house prices given the multivariate treatment intensities and the estimated GPS as provided by equation (20). Because there is no empirical interpretation of the estimated coefficients and all interaction terms are included in a third-order polynomial specification, we do not report the estimated coefficients here. The likelihood ratio test shows that including the GPS leads to a better model specification for estimating the dose-response function, with a $\chi^{2}$ of 1941 . We reject the null hypothesis that the GPS does not improve the specification, with a $p$-value less than 0.1 percent.

The GPS is based on the assumption of an underlying normal distribution of the data. A Henze-Zirkler multivariate normality test of a random 10 percent sample of the errors of the GPS estimation shows that the conditional treatments are not multivariate normally distributed. The univariate Q-Q plots (Figure 6) of the residuals show that the non-normality in the data is present for all treatments. The Q-Q plots show high kurtosis for all treatments, especially in the left tails, but the effect is most apparent for restaurant diversity. In addition to the requirement of a normal distribution of residuals, we need to test the balancing of the matching procedure (see Section 3 ).

$\langle$ Figure 6]about here > 
Balancing of the matching procedure shows whether we can rely on the selection equation to satisfy a random assignment of observations to treatment levels given the characteristics of the treated observations. Stated differently, we need to make sure that the covariates in the selection equation are randomly distributed across the observations with different treatment intensities. Assessing the quality of the matching in a multivariate treatment setting is cumbersome. The matching for estimations of each of the four treatments as single treatments, independent of the other treatment intensities, shows that adjusting for the GPS improves the randomness of treatment intensities given the covariates. Implementing the propensity score thus improves the results compared to the results obtained from more conventional estimations such as OLS. We do not obtain a fully balanced sample for any treatment variable, however, which indicates that the conditional treatment intensities of the four treatments are not fully randomly distributed across locations in Amsterdam.

Figure 7 shows the dose-response function of the multivariate estimation for each treatment estimated from equation (21). ${ }^{21}$ We find evidence for the hypothesis that people value immigrantinduced, diverse consumer amenities. House prices are higher in areas with both higher levels of restaurant density and higher levels of restaurant diversity. The effect of restaurant density is the most pronounced: the difference between the lowest and highest treatment intensities of restaurant density is over $€ 1,500$ per square meter. The effect of immigrant density is moderate, and house prices are somewhat lower at higher immigrant density treatment levels. This supports the hypothesis that areas that have a relatively high number of immigrants are less attractive residential areas. Combined with the relatively small size of the effect, this result might indicate that average levels of immigrant density do not substantially impact house prices in a city like Amsterdam, where about half of the population is of immigrant descent. Finally, the dose-response functions show that house prices are higher in areas with lower immigrant diversity, between the 20th and 40th quantiles of the treatment intensity, but house prices are lower at higher immigrant diversity treatment intensities. This result supports the hypothesis that residents prefer relatively homogeneous neighborhoods. Theoretically, this can also mean homogeneity in terms of the clustering of one immigrant group. These effects are about $€ 200$ per square meter between the houses with low and high immigrant diversity treatment intensities.

\section{$\langle$ Figure 7 about here >}

The level of the effect of all treatments lies around the average per square meter house price in Amsterdam $(€ 3,435)$. The dose-response functions thus point toward some subtle mechanisms at work in a consumer city, which can be better understood if we look at the trade-off between the treatment of immigrants and restaurants.

\subsection{Trade-off}

Figure 8 depicts the dose-response function of the joint estimation of the density of restaurants and immigrants ${ }^{22}$ In Figure 8 , the effect of increasing immigrant density on house prices is negative at

\footnotetext{
${ }^{21}$ The predicted outcome variables by the regression model are in logs and we recalculate the logs by taking the exponential of the outcome. This, however, leads to an underestimation of the expected house prices and the expected value needs to be corrected using the variance of the residuals of the regression. The correction factor in our model is negligible (1.03), and we therefore use the exponential of the outcome. See Wooldridge (2013) for more information.

${ }^{22}$ The contour plot and dose-response function is plotted for the values of the immigrant density and restaurant density between the 5 th and the 90 th percentiles.
} 
low levels of restaurant density and the presence of immigrants thus has a negative effect on house prices. Access to ethnic restaurants has a positive effect on house prices, as we showed for the conditional dose-response functions. If the immigrant density is low, the effect of a higher number of restaurants on house prices is positive.

\section{$\langle$ Figure 8 about here 〉}

These results show that a higher number of restaurants can compensate for the negative effect of the presence of immigrants and that the hypothesized trade-off between restaurant and immigrant density is present in Amsterdam. This trade-off exists at all levels of immigrant density for lower house prices, and above an immigrant density of 3 for higher house prices and occurs for most observations in our data. Most of our observations in the data are around the mean value of immigrant density, 4.05, and the mean value of restaurant density, 1.28, which is also shown in the hexabin density plot in Figure 4 . The above described trade-off effect is also visible in Figure 7. Above the 50th percentile, where the restaurant and immigrant density intersect, the effect of restaurant density on house prices is positive and the effect of immigrant density on house prices is negative. The combined effect thus results in a trade-off. As the values of the treatments are defined as above or below the average in Amsterdam (above or below 1), we find that this trade-off mostly exists in areas that have an above average immigrant and restaurant density.

The results of the trade-off described in Figure 8 are conditional on the treatment intensities of restaurant and immigrant diversity as observed in the data, i.e., around the mean of the restaurant and immigrant diversity. In order to investigate the effect of restaurant and immigrant diversity on the trade-off between the presence of immigrants and restaurants, we have also estimated the doseresponse functions for low (around the value of the first quartile) and high (around the value of the third quartile) levels of immigrant and restaurant diversity ${ }^{23}$ The overall trade-off effect remains in tact at low levels of immigrant diversity. A higher immigrant density has a negative effect on house prices which can be compensated by access to a higher number of restaurants. However, with a high immigrant diversity, the compensating effect of restaurant density almost diminishes. At the mean values of immigrant and restaurant density, which coincides with the contour lines of per square meter house prices between $€ 3,200$ and $€ 3,400$, the trade-off is low and the overall negative effect of immigrant density on house prices is higher. The results for the trade-off between immigrant and restaurant diversity conditional on whether the restaurant diversity is low or high shows a moderating effect. At a low level of restaurant diversity, the trade-off at the mean values of immigrant and restaurant diversity is more or less equal to trade-off if the restaurant diversity is average. For high restaurant diversity, the effect of restaurant density on house prices is higher than with an average restaurant diversity and the trade-off between restaurant and immigrant density is somewhat higher at the average house price in Amsterdam.

\section{$\langle$ Figure 9 about here 〉}

We also find a clear trade-off between immigrant density and restaurant diversity at all values of immigrant density above the Amsterdam average (Figure 9) and for most observations in our dataset (with a mean value of immigrant density of 4.05 and a mean restaurant diversity of 0.91 ). However, given the distribution of restaurant diversity, this trade-off holds for areas with a lower

${ }^{23}$ The results are not reported here but available upon request. 
than Amsterdam average restaurant diversity (below 1). In addition, the trade-off between immigrant density and restaurant diversity happens at a much smaller scale of house prices than the trade-off between immigrant and restaurant density. The increase in diversity needs to be relatively large compared to the increase in restaurant density in order to compensate for the negative effect of immigrant density on house prices.

\section{Conclusion}

It is often hypothesized that immigrants affect the utility of living in large cities because they foster the access to consumer products that are available. We developed a simple spatial equilibrium model of an intra-city housing market, to show that differences in utility between neighborhoods can be explained by differences in immigrant population externalities and access to diversified immigrant consumer goods. These effects can be either positive or negative, implying the existence of potential trade-offs in the appreciation of the ethnic consumer goods on the one hand and the presence of the ethnic population on the other hand. Our empirical analysis for the city of Amsterdam indeed confirms the existence of such a trade-off, with people preferring to live apart but consume together.

More specifically, our results show that there are compensating effects of restaurant density and restaurant diversity on immigrant density. We also find that amenity-rich areas in terms of restaurants are more attractive (measured by house prices) if these amenities are diverse. The effect of restaurant density on house prices is especially substantial, and in a city like Amsterdam this effect seems to be much more apparent than that of the population composition. However, the compensating effect of the access to ethnic restaurants on the presence of immigrants diminishes if the immigrant population is very diverse.

We apply a relatively novel identification strategy in this paper. Although we cannot fully account for the non-randomness in the treatment intensities in our data, the estimations manage to substantially reduce the endogeneity bias apparent in this type of research. A couple of questions raised in this paper warrant further research. While we have established the patterns evident at specific spatial scales (smaller effects for population and larger effects for restaurants), we do not know whether these spatial scales also hold for different cities or whether they depend on city size and transportation costs. Further research into the internal structure of cities and the connectedness between neighborhoods and between areas with different user functions, such as residential areas, shopping areas, etc., is needed to answer this question. In addition, the results in this paper not only raise the question of how the internal structures of cities foster the utility derived from ethnic density or diversity, but also how these structures can affect the utility derived from immigrants. Our research is a cross-sectional model of trade-offs in neighborhoods. Further research with a dynamic model may provide insights into the changes of trade-offs and the underlying causes for these trade-offs. Another question that can be raised from the results presented in this paper is not only how well these results fit to other cities that are as ethnically diverse as Amsterdam, but

also how well these results fit to cities that are much less ethnically diverse and that might have different segregation patterns. 


\section{References}

Accetturo, A., F. Manaresi, S. Mocetti, and E. Oliveiri (2014). Don't Stand so Close to me: The Urban Impact of Immigration. Regional Science and Urban Economics 45(1), 45-56.

Bakens, J., P. Mulder, and P. Nijkamp (2013). Economic Impacts of Cultural Diversity in the Netherlands: Productivity, Utility, and Sorting. Journal of Regional Science 53(1), 8-36.

Bayer, P., R. McMillan, and K. S. Rueben (2004). What Drives Racial Segregation? New Evidence Using Census Microdata. Journal of Urban Economics 56(3), 514-535.

Becker, S. O., P. H. Egger, and M. von Ehrlich (2012). Too Much of a Good Thing? On the Growth Effects of the EU's Regional Policy. European Economic Review 56(4), 648-668.

Berry, S. and J. Waldfogel (2010). Product Quality and Market Size. Journal of Industrial Economics 58(1), 1-31.

Borjas, G. J. (1995). Ethnicity, Neighborhoods, and Human Capital Externalities. American Economic Review 85(3), 365-390.

Brookhart, M. A., S. Schneeweiss, K. J. Rothman, R. J. Glynn, J. Avorn, and T. Stürmer (2006). Variable Selection for Propensity Score Models. American Journal of Epidemiology 163(12), $1149-1156$.

Card, D., A. Mas, and J. Rothstein (2008). Tipping and the Dynamics of Segregation. Quaterly Journal of Economics 123(1), 177-218.

Cutler, D. M., E. L. Glaeser, and J. L. Vigdor (1999). The Rise and Decline of the American Ghetto. Journal of Political Economy 107(3), 455-506.

De La Roca, J., I. G. Ellen, and K. M. O'Regan (2014). Race and Neighborhoods in the 21st century: What does Segregation mean Today? Regional Science and Urban Economics 47, $138-151$.

Dixit, A. K. and J. E. Stiglitz (1975). Monopolistic Competition and Optimum Product Diversity. In S. Brakman and B. J. Heijdra (Eds.), The Monopolistic Competition Revolution in Retrospect, pp. 89-120. Cambridge 2004: Cambridge University Press. Reprinted.

Dixit, A. K. and J. E. Stiglitz (1977). Monopolistic Competition and Optimum Product Diversity. American Economic Review 67(3), 297-308.

Egger, P. H. and M. Von Ehrlich (2013). Generalized Propensity Scores for Multiple Continuous Treatment Variables. Economics Letters 119(1), 32-34.

Feser, E. (2013). Isserman's Impact: Quasi-Experimental Comparison Group Designs in Regional Research. International Regional Science Review 36(1), 44-68.

Fryges, H. and J. Wagner (2008). First Evidence and Productivity Growth: Exports Treatment from a Continuous Approach. Review of World Economics / Weltwirtschaftliches Archiv 144(4), $695-722$. 
George, L. M. and J. Waldfogel (2006). The "New York Times" and the Market for Local Newspapers. American Economic Review 96(1), 435-447.

Glaeser, E. L., J. Kolko, and A. Saiz (2001). Consumer City. Journal of Economic Geography 1(1), $27-50$.

De Groot, H. L. F., G. Marlet, C. N. Teulings, and W. Vermeulen (2010). Stad en Land. The Hague: CPB Netherlands Bureau for Economic Policy Analysis.

Hårsman, B. and J. M. Quigley (1995). The Spatial Segregation of Ethnic and Demographic groups: Comparative Evidence from Stockholm and San Francisco. Journal of Urban Economics 37(1), $1-16$.

Henze, N. and B. Zirkler (1990). A Class of Invariant Consistent Tests for Multivariate Normality. Communications in Statistics - Theory and Methods 19(10), 3595-3617.

Hirano, K. and G. W. Imbens (2004). The Propensity Score with Continuous Treatments. In A. Gelman and X.-L. Meng (Eds.), Applied Bayesian Modeling and Causal Inference from Incomplete Data Perspectives, pp. 73-84. West Sussex: Wiley InterScience.

Ioannides, Y. M. and J. E. Zabel (2008). Interactions, Neighborhood Selection and Housing Demand. Journal of Urban Economics 63(1), 229-252.

Mazzolari, F. and D. Neumark (2012). Immigration and Product Diversity. Journal of Population Economics 25(3), 1107-1137.

Mitze, T. (2014). Does Regional Science need an Experimentalist Buzz? Regional Studies, Regional Science 1(1), 51-59.

Ottaviano, G. I. P. and G. Peri (2005). Cities and Cultures. Journal of Urban Economics 58(2), $304-337$.

Ottaviano, G. I. P. and G. Peri (2006). The Economic Value of Cultural Diversity: Evidence from US Cities. Journal of Economic Geography 6(1), 9-44.

Rosenbaum, P. R. and D. B. Rubin (1983). The Central Role of the Propensity Score in Observational Studies for Causal Effects. Biometrika 70(1), 41-55.

Rubin, D. B. and N. Thomas (1996). Matching Using Estimated Propensity Scores: Relating Theory to Practice. Biometrics 52(1), 249-264.

Schiff, N. (2015). Cities and Product Variety: Evidence from Restaurants. Journal of Economic Geography 15(6), 1085-1123.

Vermeulen, W., C. N. Teulings, G. Marlet, and H. L. F. de Groot (2016). GroeiछKrimp. Nijmegen: VOC Uitgevers.

Waldfogel, J. (2008). The Median Voter and the Median Consumer: Local Private Goods and Population Composition. Journal of Urban Economics 63(2), 567-582.

Wooldridge, J. M. (2013). Mason, OH: South-Western. 


\section{Tables and Figures}

Table 1: Descriptive statistics

\begin{tabular}{|c|c|c|c|c|}
\hline & mean & st. dev. & $\min$. & $\max$. \\
\hline Price per square meter in $€$ & 3,435 & 1,000 & 770 & 12,190 \\
\hline Relative immigrant density ${ }^{a}$ & 4.05 & 2.16 & 0.05 & 13.05 \\
\hline Relative restaurant density ${ }^{\mathrm{a}}$ & 1.28 & 1.47 & 0.08 & 9.11 \\
\hline Relative immigrant diversity ${ }^{\mathrm{a}}$ & 0.85 & 0.15 & 0.14 & 1.02 \\
\hline Relative restaurant diversity ${ }^{\mathrm{a}}$ & 0.91 & 0.16 & 0.18 & 1.20 \\
\hline Share social rent pc6 & 0.24 & 0.32 & 0 & 1 \\
\hline Share owner occupied pc6 & 0.43 & 0.29 & 0 & 1 \\
\hline Population density $\mathrm{km}^{2}$ & 10,930 & 4,346 & 322 & 20,510 \\
\hline Distance to Amsterdam CS station (meter) & 3,617 & 2,01 & 250 & 1,162 \\
\hline Distance to top10 (meter) $)^{\mathrm{b}}$ & 32,500 & 18,167 & 11,000 & 108,000 \\
\hline Distance to nearest metro station (meter) & 1,660 & 925 & 21 & 4,889 \\
\hline
\end{tabular}

Data source: OIS and NVM.

${ }^{a}$ We use the diversity and density relative to the overall diversity and density of the immigrant population and restaurants in Amsterdam. Because of this scaling, the distribution of the measures is not normally distributed around 1, which would have been the case if we had used the measures relative to the density or diversity in the sample. The immigrant density and diversity are measured in a 250 meter radius around the dwelling. The restaurant density and diversity is measured in a 1000 meter radius around the dwelling.

$\mathrm{b}$ The ten main tourist attractions are based on visitor numbers. We use total distance from the dwelling to the ten attractions. The ten tourist attractions used are the Rijksmuseum, Van Gogh Museum, Anne Frank Huis, Artis Zoo, Stedelijk Museum, Madame Tussauds, Heineken Experience, Nemo Science Center, Hermitage, and Venustempel Museum. 
Table 2: Dummy variables

\begin{tabular}{llr}
\hline & Category & Observations \\
\hline Inside A10 highway ring & yes & 32,621 \\
& no & 7,519 \\
Garden & yes & 2,852 \\
nransaction year & 2006 & 37,288 \\
& 2007 & 7,785 \\
& 2008 & 7,640 \\
no & 2009 & 6,385 \\
Number of rooms & 2010 & 6,179 \\
& 2011 & 6,279 \\
Type of dwelling & 3 or less & 5,872 \\
& 4 & 27,981 \\
& 5 or more & 7,505 \\
& Simple house & 4,654 \\
& Canal house & 153 \\
& Bungalow & 209 \\
& Villa & 29 \\
& Ground floor apartment & 94 \\
& Upper floor apartment & 5,640 \\
& Gallery apartment & 24,732 \\
& Maisonette & 1,457 \\
Portico flat & 1,464 \\
& Ground and upper floor apartment & 3,035 \\
& Single-family house & 285 \\
& Town house & 2,266 \\
& Rest category & 734 \\
& & 42 \\
\hline & & 40,140 \\
\hline
\end{tabular}

Data source: OIS and NVM. 
Table 3: Correlations between relative treatments ${ }^{\mathrm{a}}$

\begin{tabular}{lrrrr}
\hline & $\begin{array}{c}\text { Immigrant } \\
\text { density }\end{array}$ & $\begin{array}{c}\text { Restaurant } \\
\text { density }\end{array}$ & $\begin{array}{c}\text { Immigrant } \\
\text { diversity }\end{array}$ & $\begin{array}{c}\text { Restaurant } \\
\text { diversity }\end{array}$ \\
\hline Restaurant density & $-0.14^{* * *}$ & & & \\
Immigrant diversity & $0.45^{* * *}$ & $-0.55^{* * *}$ & & \\
Restaurant diversity & $0.36^{* * *}$ & $0.29^{* * *}$ & $0.04^{* * *}$ & \\
\hline
\end{tabular}

Data source: OIS and NVM.

${ }^{a}$ The statistical significance of the correlation coefficients is indicated by ***, **, * for the $0.01,0.05$, and 0.1 significance levels, respectively. 
Table 4: Conditional treatment estimates ${ }^{\mathrm{a}}$

\begin{tabular}{|c|c|c|c|c|}
\hline & \multicolumn{2}{|c|}{ Immigrant (ln) } & \multicolumn{2}{|c|}{ Restaurant (ln) } \\
\hline & coef. & st. err. & coef. & st. err \\
\hline \multicolumn{5}{|l|}{ Relative density } \\
\hline Garden & -0.000 & 0.000 & & \\
\hline Distance Amsterdam CS station (ln) & $-0.132^{* * *}$ & 0.008 & $-0.112^{* * *}$ & 0.007 \\
\hline Distance nearest metro station (ln) & $-0.085^{* * *}$ & 0.003 & $-0.033^{* * *}$ & 0.003 \\
\hline Distance top10 $(\ln )$ & $0.653^{* * *}$ & 0.010 & $-1.922^{* * *}$ & 0.009 \\
\hline Inside A10 highway ring & $-0.055^{* * *}$ & 0.009 & $-0.746^{* *}$ & 0.008 \\
\hline Share social rent pc6 & $0.334^{* * *}$ & 0.009 & $-0.056^{* * *}$ & 0.008 \\
\hline Share owner occupied pc6 & $-0.130^{* * *}$ & 0.009 & $-0.119^{* * *}$ & 0.009 \\
\hline Population density $\mathrm{km}^{2}$ & $1.017^{* * *}$ & 0.007 & $-0.104^{* * *}$ & 0.006 \\
\hline Constant & $-13.010^{* * *}$ & 0.113 & $22.285^{* * *}$ & 0.104 \\
\hline Transaction year dummies & yes & & yes & \\
\hline Dwelling type dummies & yes & & yes & \\
\hline Number of rooms dummies & yes & & no & \\
\hline Observations & 40140 & & 40140 & \\
\hline Adjusted $R^{2}$ & 0.53 & & 0.81 & \\
\hline \multicolumn{5}{|l|}{ Relative diversity } \\
\hline Garden & -0.000 & 0.000 & & \\
\hline Distance Amsterdam CS station (ln) & $0.111^{* * *}$ & 0.002 & $-0.095^{* * *}$ & 0.003 \\
\hline Distance nearest metro station (ln) & $0.009^{* * *}$ & 0.001 & $-0.020^{* * *}$ & 0.001 \\
\hline Distance top10 (ln) & & & 0.003 & 0.004 \\
\hline Inside A10 highway ring & $0.005^{* * *}$ & 0.004 & $-0.056^{* * *}$ & 0.004 \\
\hline Share social rent pc6 & $0.230^{* * *}$ & 0.004 & $0.061^{* * *}$ & 0.003 \\
\hline Share owner occupied pc6 & $0.067^{* * *}$ & 0.004 & $0.023^{* * *}$ & 0.004 \\
\hline Population density $\mathrm{km}^{2}$ & $0.087^{* * *}$ & 0.003 & $0.231^{* * *}$ & 0.003 \\
\hline Constant & $-2.036^{* * *}$ & 0.032 & $-1.347^{* * *}$ & 0.043 \\
\hline Transaction year dummies & yes & & yes & \\
\hline Dwelling type dummies & yes & & & \\
\hline Number of rooms dummies & yes & & no & \\
\hline Observations & 40140 & & 40140 & \\
\hline Adjusted $R^{2}$ & 0.25 & & 0.37 & \\
\hline
\end{tabular}

Data source: OIS and NVM.

a The statistical significance of coefficients is indicated by ***, **, and * for the $0.01,0.05$, and 0.1 significance levels, respectively. 


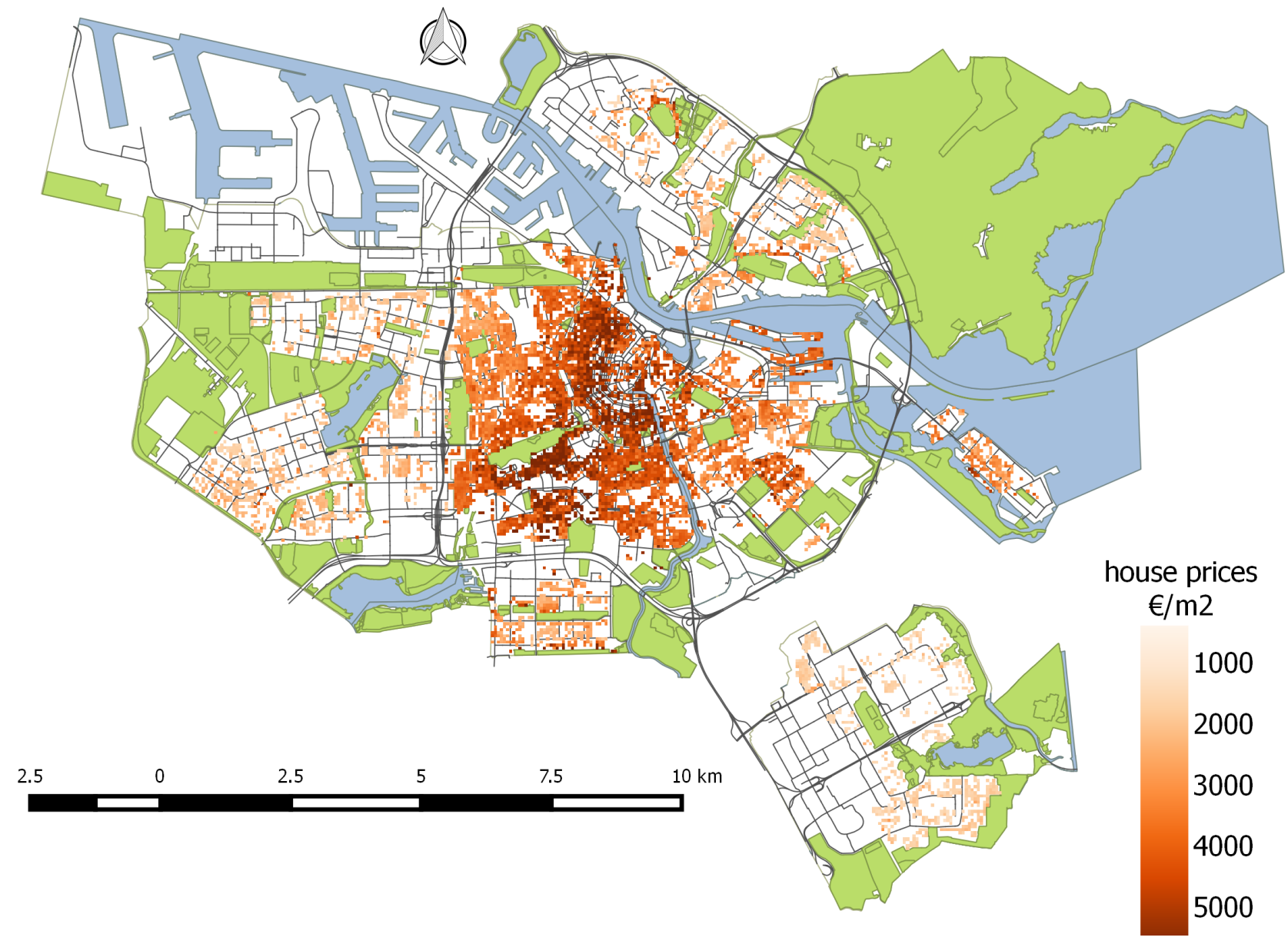

Data Source: NVM.

Figure 1: Average per square meter house prices between $2006-2011$ in constant 2008 prices in $59 \times 59$ meter grid cells 

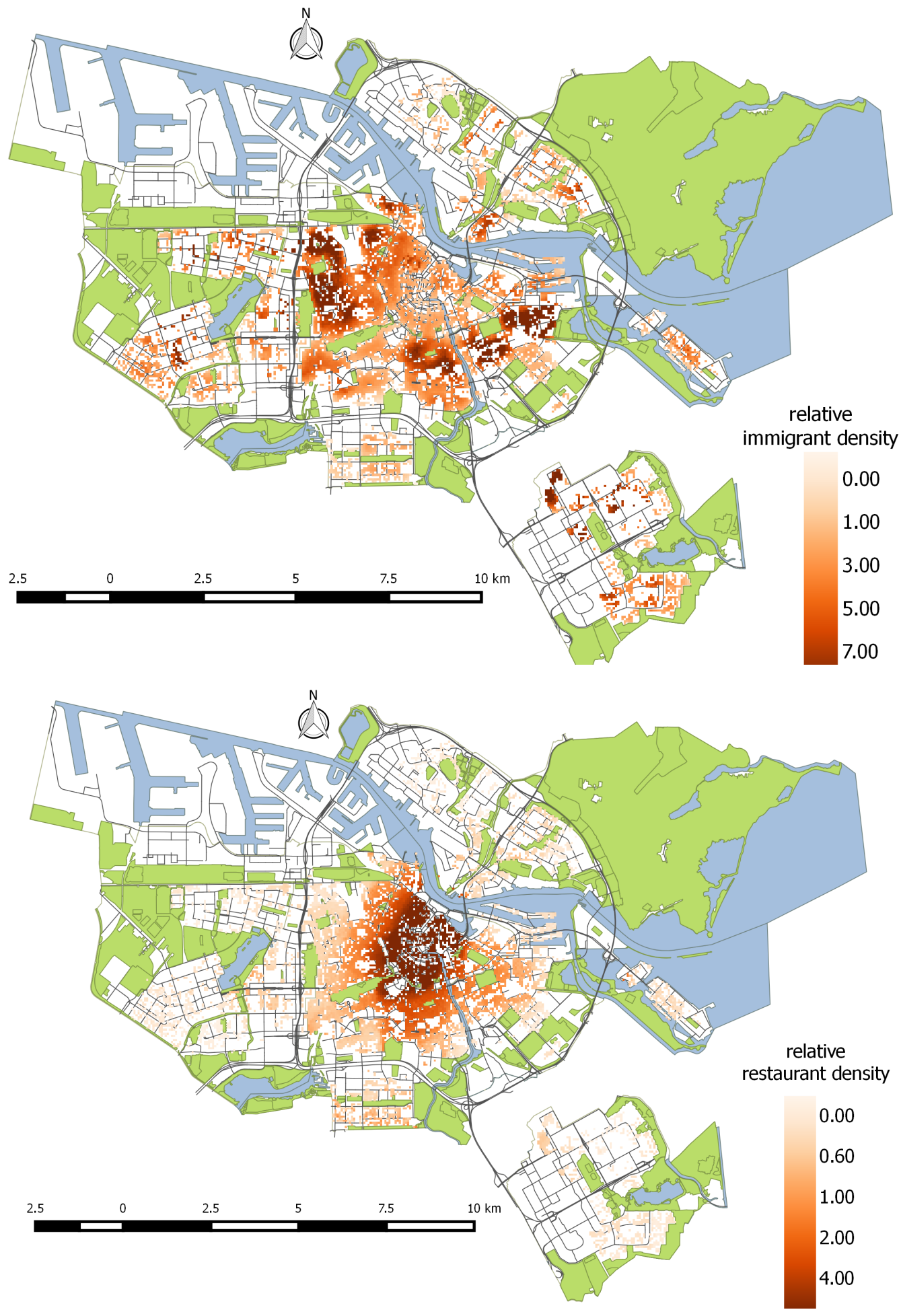

Data Source: OIS and NVM.

Figure 2: Average density of immigrants (above) and restaurants (below) in $59 \times 59$ meter grid cells 

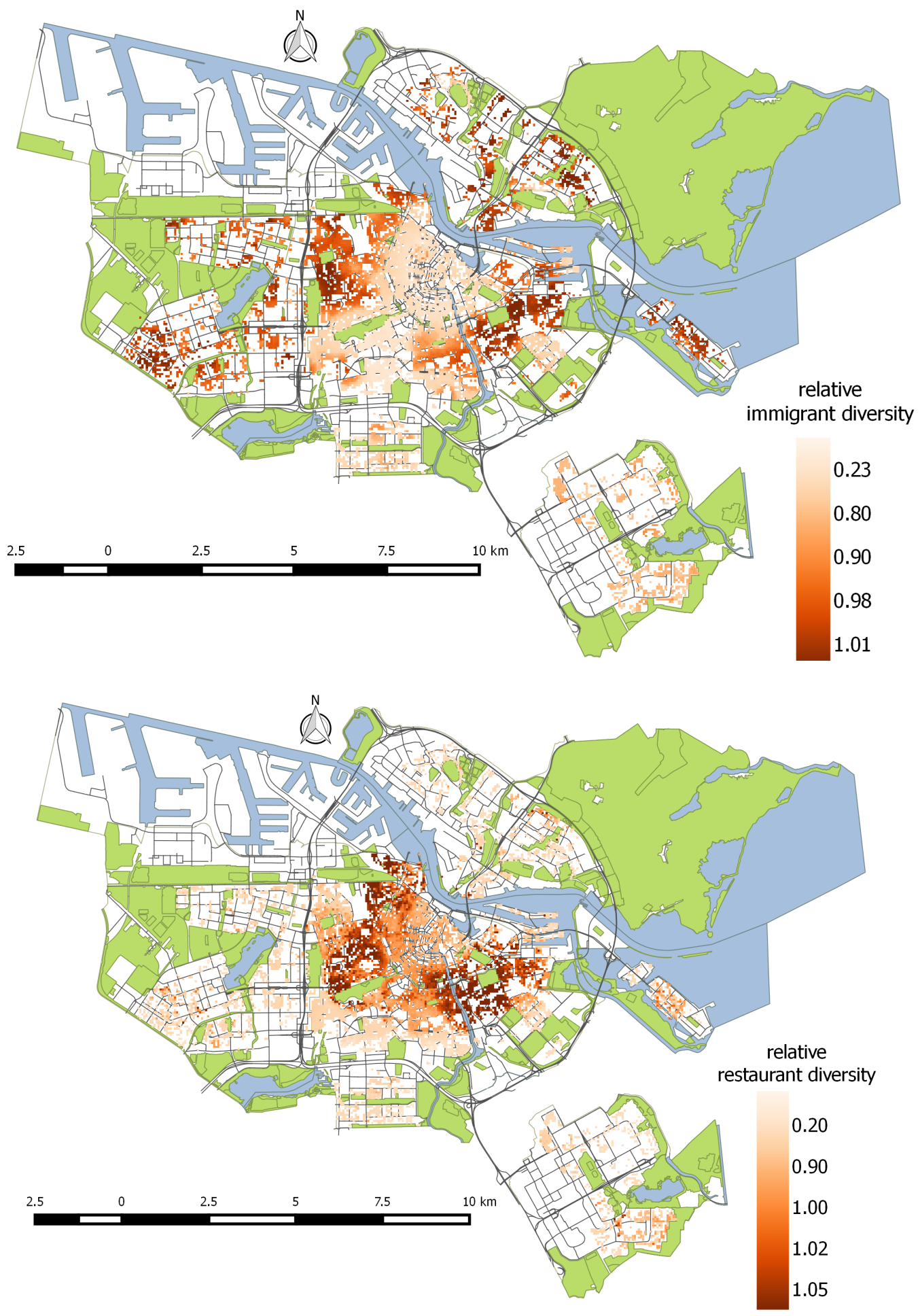

Data Source: OIS and NVM.

Figure 3: Average diversity of immigrants (above) and restaurants (below) in $59 \times 59$ meter grid cells 
Hexagonal Binning

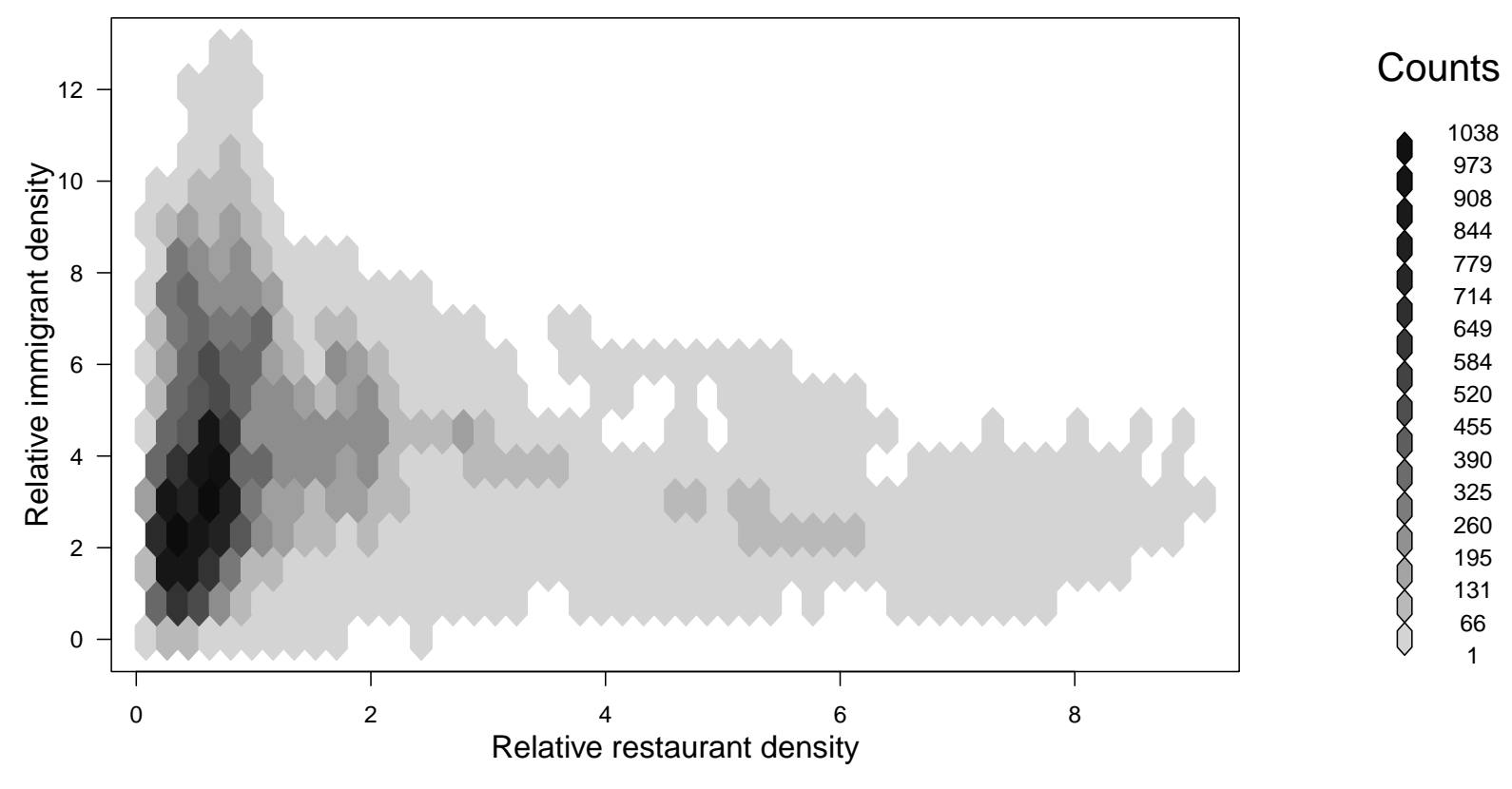

Data Source: OIS and NVM.

Figure 4: Hexagon plot of the relative immigrant and relative restaurant density 


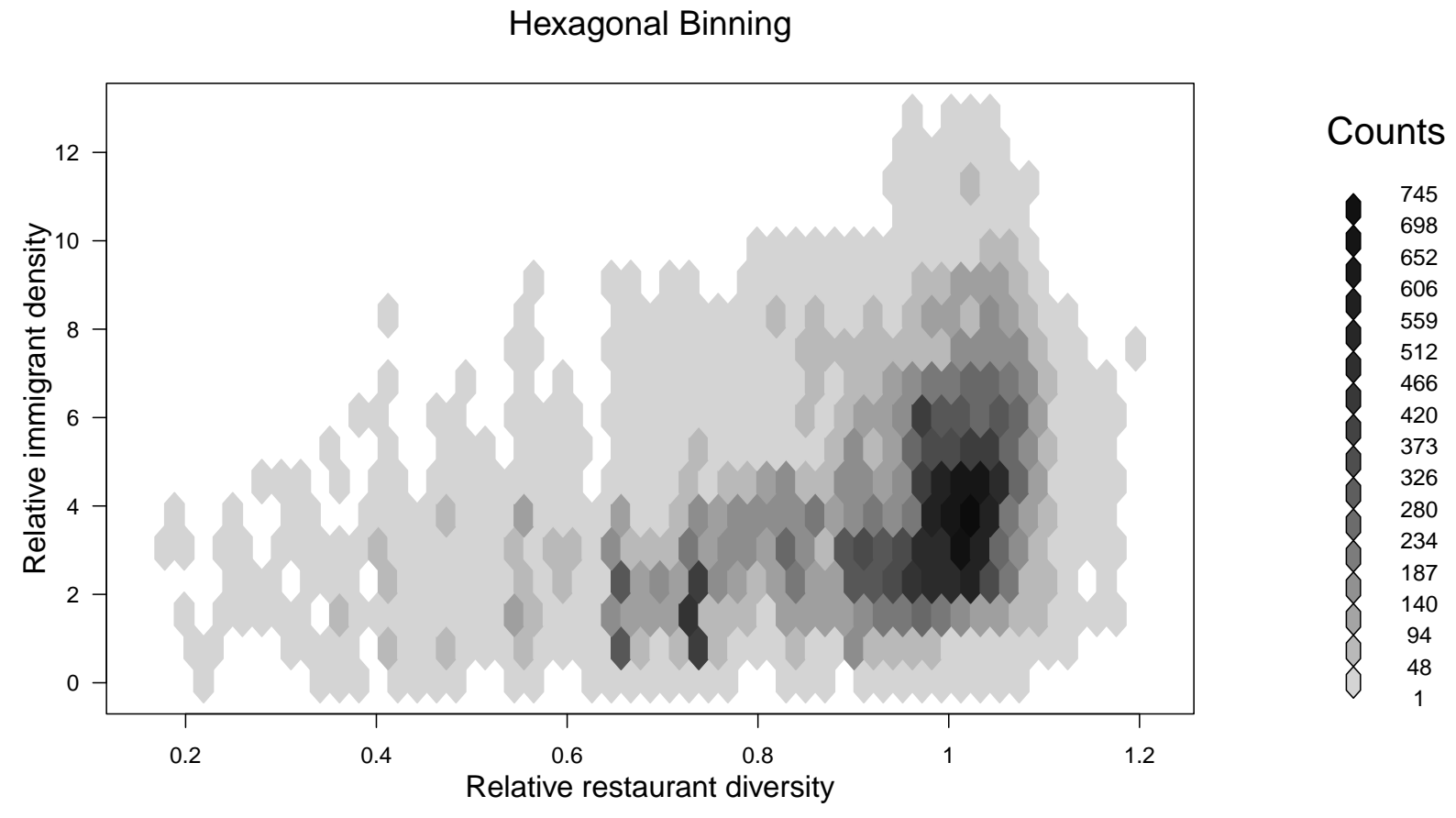

Data Source: OIS and NVM.

Figure 5: Hexagon plot of the relative immigrant density and relative restaurant diversity 

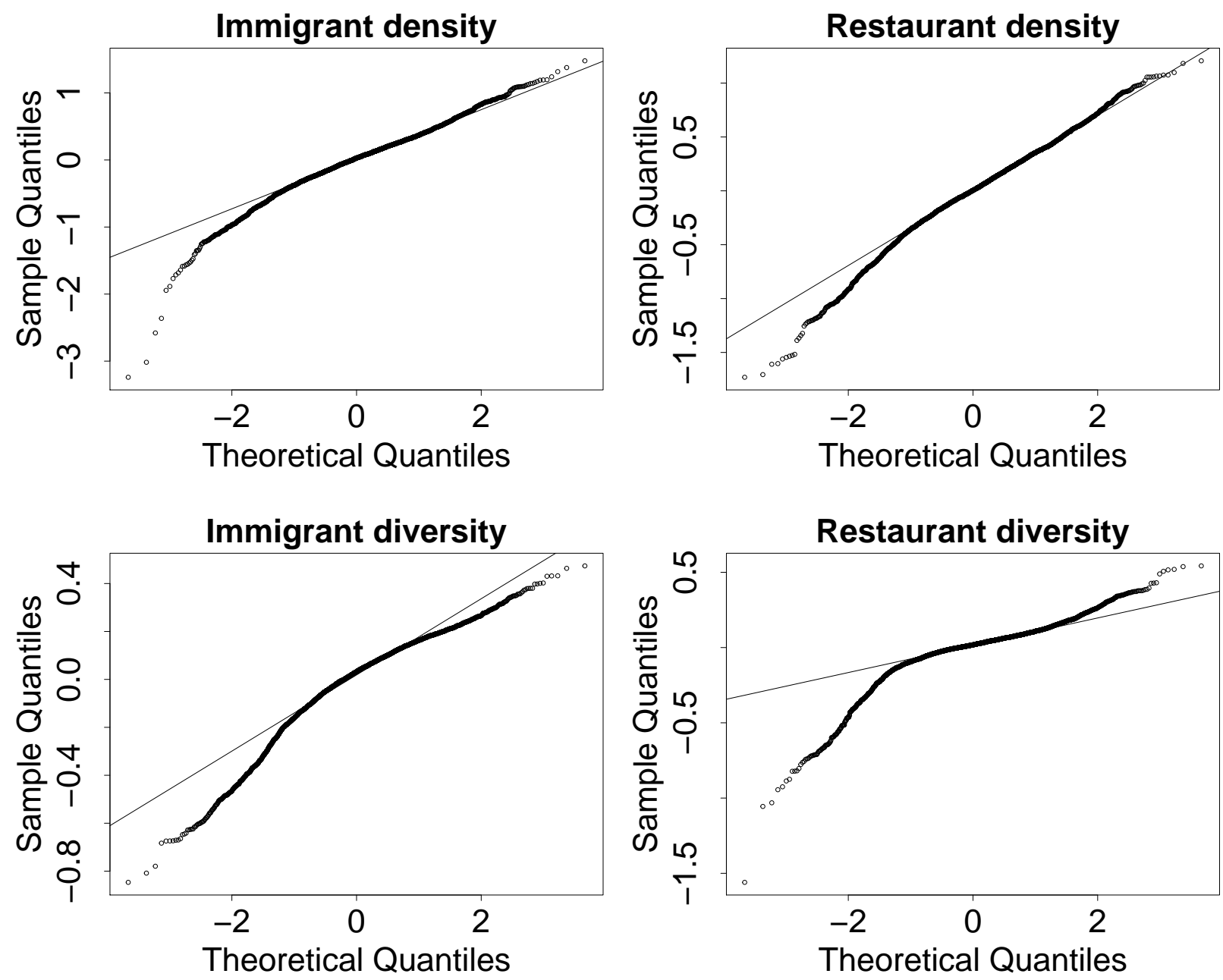

Data Source: OIS and NVM.

Figure 6: Q-Q plots conditional multivariate treatments 


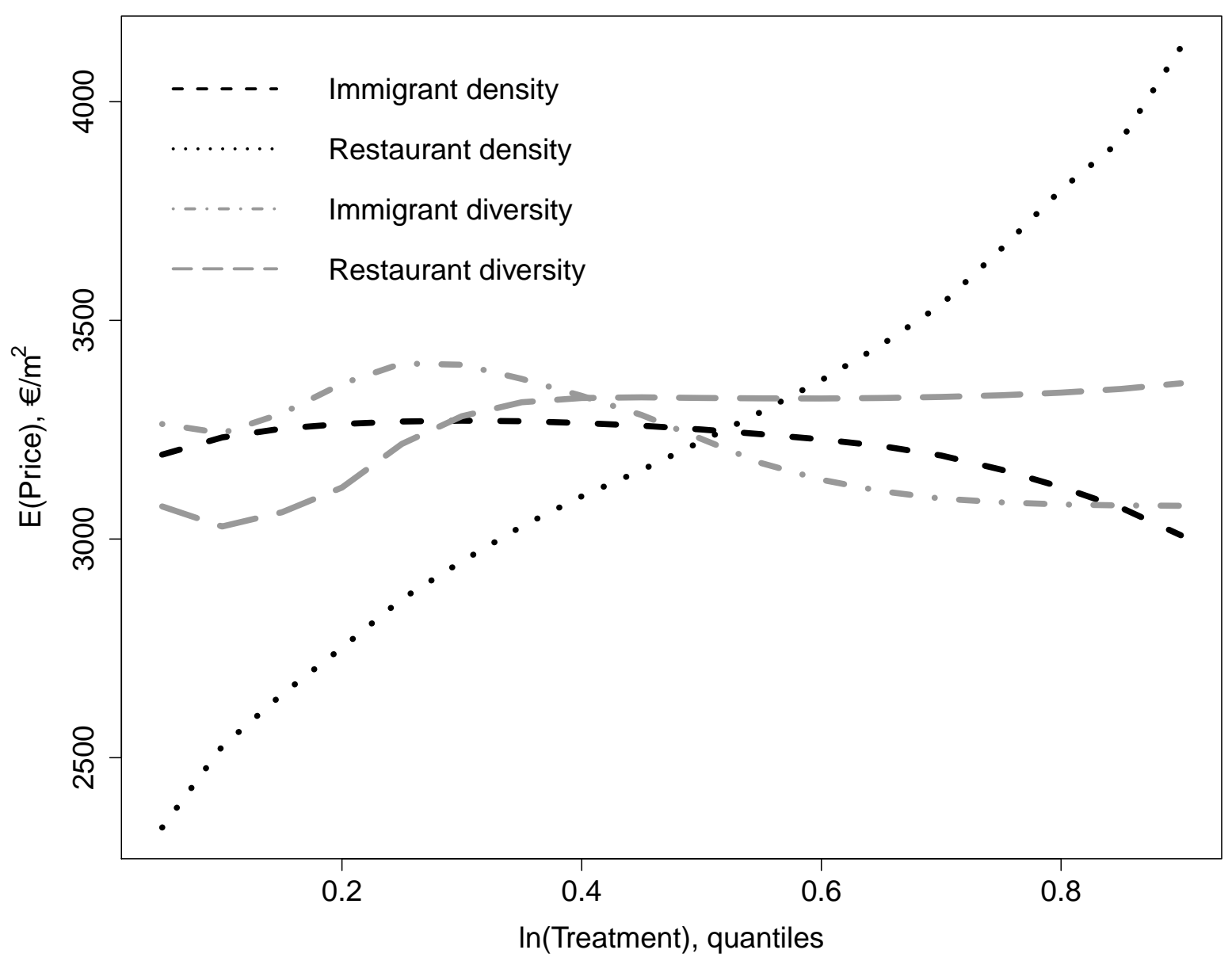

Data Source: OIS and NVM.

Figure 7: Conditional multivariate dose-response functions of relative treatments 


\section{$E\left(\right.$ Price),$€ / m^{2}$}
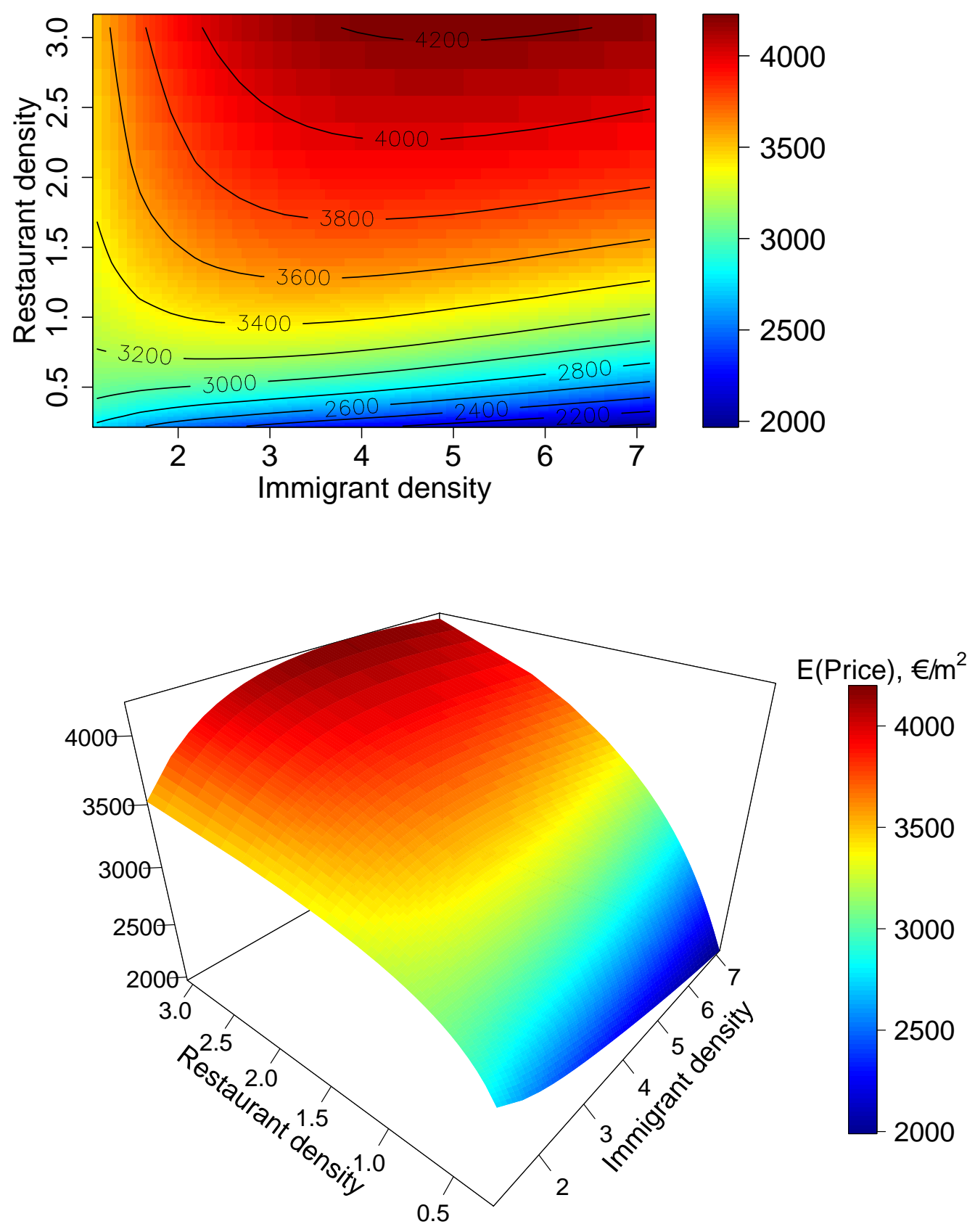

Data source: OIS and NVM.

Figure 8: Multivariate contour plot and dose-response function for relative restaurant and relative immigrant density trade-off 
$\mathrm{E}$ (Price), $€ / \mathrm{m}^{2}$
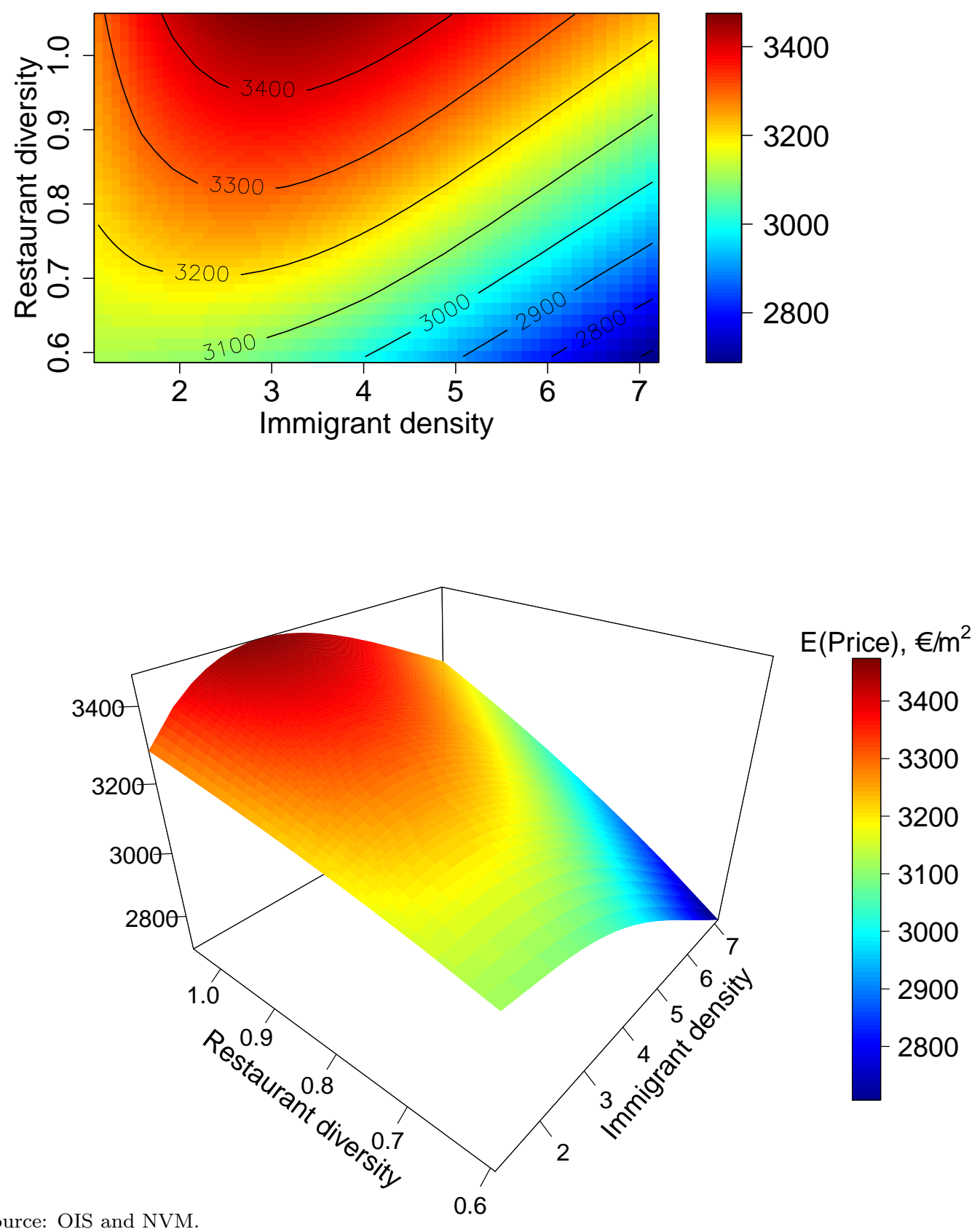

Data source: OIS and NVM.

Figure 9: Multivariate contour plot and dose-response function for relative restaurant diversity and relative immigrant density trade-off 